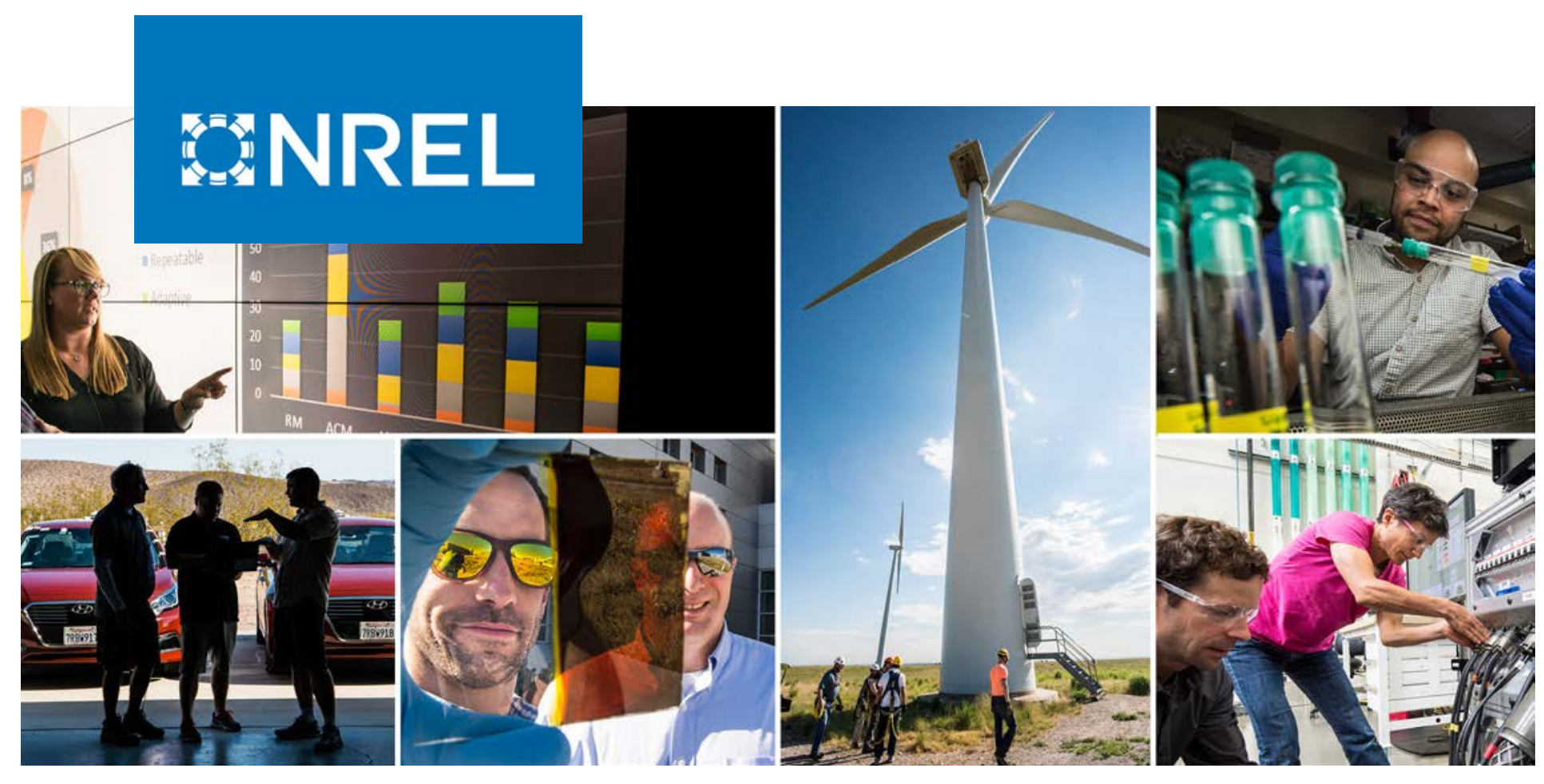

\title{
The Industry Energy Tool (IET): Documentation
}

Colin McMillan and Vinayak Narwade

National Renewable Energy Laboratory

NREL is a national laboratory of the U.S. Department of Energy

Office of Energy Efficiency \& Renewable Energy

Operated by the Alliance for Sustainable Energy, LLC

This report is available at no cost from the National Renewable Energy Laboratory (NREL) at www.nrel.gov/publications.

\section{Technical Report}

NREL/TP-6A20-71990

November 2018 


\title{
EAREL
}

\section{The Industry Energy Tool (IET): Documentation}

\author{
Colin McMillan and Vinayak Narwade
}

National Renewable Energy Laboratory

\section{Suggested Citation}

McMillan, Colin and Vinayak Narwade. 2018. The Industry Energy Tool (IET):

Documentation. Golden, CO: National Renewable Energy Laboratory.

NREL/TP-6A20-71990. https://www.nrel.gov/docs/fy19osti/71990.pdf.

NREL is a national laboratory of the U.S. Department of Energy Office of Energy Efficiency \& Renewable Energy Operated by the Alliance for Sustainable Energy, LLC

This report is available at no cost from the National Renewable Energy Laboratory (NREL) at www.nrel.gov/publications.

Contract No. DE-AC36-08GO28308
Technical Report NREL/TP-6A20-71990 November 2018

National Renewable Energy Laboratory 15013 Denver West Parkway Golden, CO 80401

303-275-3000 • www.nrel.gov 


\section{NOTICE}

This work was authored by the National Renewable Energy Laboratory, operated by Alliance for Sustainable Energy, LLC, for the U.S. Department of Energy (DOE) under Contract No. DE-AC36-08GO28308. Funding provided by U.S. Department of Energy Office of Energy Efficiency and Renewable Energy Office of Strategic Programs. The views expressed herein do not necessarily represent the views of the DOE or the U.S. Government.

This report is available at no cost from the National Renewable Energy Laboratory (NREL) at www.nrel.gov/publications.

U.S. Department of Energy (DOE) reports produced after 1991 and a growing number of pre-1991 documents are available free via www.OSTI.gov.

Cover Photos by Dennis Schroeder: (clockwise, left to right) NREL 51934, NREL 45897, NREL 42160, NREL 45891, NREL 48097, NREL 46526.

NREL prints on paper that contains recycled content. 


\section{Acknowledgments}

The authors thank multiple reviewers for their helpful comments and technical review of this report, including Sam Baldwin, Steve Capanna, Paul Donohoo-Vallett, Kara Podkaminer, Ookie Ma, Paul Spitsen, and Brian Walker of the U.S. Department of Energy (DOE); Bob Adler and Tom Lorenz of the U.S. Energy Information Administration; Bill Morrow of the Lawrence Berkeley National Laboratory; and Elaine Hale, Trieu Mai, Robert Margolis, and Gian Porro of the National Renewable Energy Laboratory. We also thank Mike Meshek for editorial support. Any errors or omissions are the sole responsibility of the authors. 


\section{List of Acronyms}

$\begin{array}{ll}\text { AEO } & \text { Annual Energy Outlook } \\ \text { CBP } & \text { County Business Patterns } \\ \text { EIA } & \text { U.S. Energy Information Administration } \\ \text { eGRID } & \text { Emissions and Generation Resource Integrated Database } \\ \text { EPA } & \text { U.S. Environmental Protection Agency } \\ \text { FIPS } & \text { Federal Information Processing Standards } \\ \text { GHG } & \text { greenhouse gas } \\ \text { GHGRP } & \text { Greenhouse Gas Reporting Program } \\ \text { IET } & \text { Industry Energy Tool } \\ \text { IO } & \text { input-output } \\ \text { IPF } & \text { iterative proportional fitting } \\ \text { LPG-NGL } & \text { Liquid petroleum gas-natural gas liquids } \\ \text { MECS } & \text { Manufacturing Energy Consumption Survey } \\ \text { MMTCO2e } & \text { million metric tons carbon dioxide equivalent } \\ \text { NAICS } & \text { North American Industrial Classification System } \\ \text { NEMS } & \text { National Energy Modeling System } \\ \text { NREL } & \text { National Renewable Energy Laboratory } \\ \text { TBtu } & \text { trillion British thermal units } \\ \text { TPC } & \text { technology possibility curve } \\ \text { UEC } & \text { unit energy consumption } \\ \text { USDA } & \text { U.S. Department of Agriculture }\end{array}$




\section{Executive Summary}

Studies of industrial energy use typically mention the sector's heterogeneity and complexity as modeling barriers. One of the more significant impediments to analyzing and building models of U.S. industrial energy use is the lack of current disaggregated data. The Industry Energy Tool (IET) and its foundational data address some of these barriers

The IET has been developed as an open-source, transparent, and flexible tool for exploring industrial sector energy and emissions scenarios. The IET takes a simplified approach to developing scenario projections of energy and emissions by allowing users to modify prepopulated inputs for achieved energy efficiency, rate of equipment stock turnover, and future penetration of renewable electricity. In addition to its transparency and flexibility, the strengths of the IET lie in its geographically and operationally disaggregated data set; estimates of coal use shown in Figure ES-1 provide an example of this geographic disaggregation. The IET's foundational data are built on energy data first calculated at the facility and end-use levels for many of the largest energy-using industries. These data are then aggregated to the county and end-use level with other publicly available data for use in scenarios estimation.

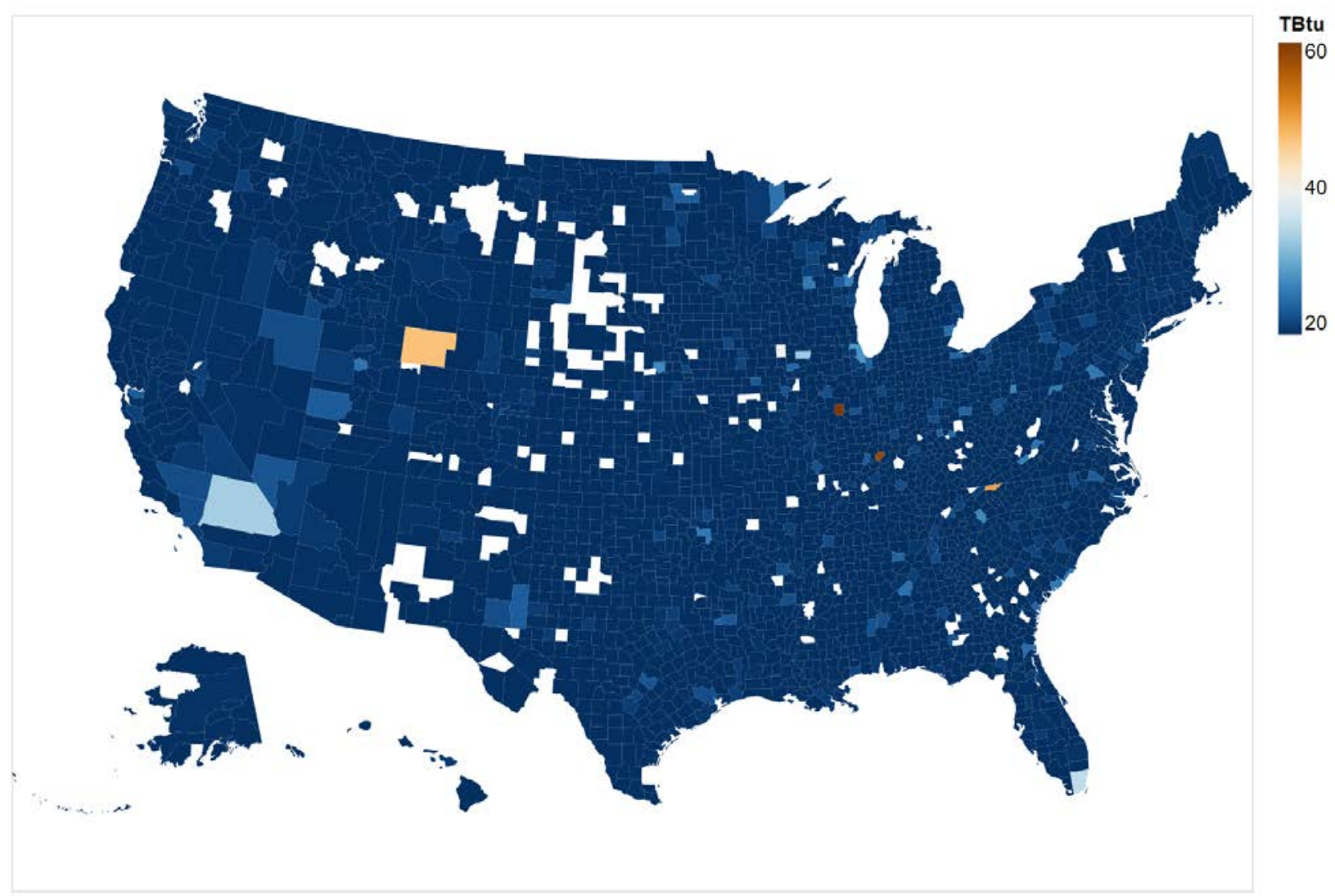

Figure ES-1. Estimated industrial coal use in 2014

White shading represents an estimated value of zero.

In this report, we detail two contributions to the current state of industry energy analysis: an industry energy data foundation that estimates detailed county-level industrial energy use in 2014 and the IET itself. The data foundation is built on facility-level calculations of energy use for the 
largest energy-using industries (vis-a-vis the largest greenhouse gas-emitting industries) and provides estimates at the four- to six-digit North American Industrial Classification System (NAICS) code level. We have further improved the operational characterization of industrial energy use by identifying temperature requirements for boiler and process heating energy use by industry.

The IET is a streamlined, transparent, open-source calculator tool for developing forwardlooking scenarios of U.S. industrial energy use at the county, state, and national level. The tool examines industry energy use and emissions to 2050 using four components: stock turnover, energy efficiency, fuel switching, and emissions. ${ }^{1}$ Projections are based on user-defined inputs and not economic optimization or other similar approaches.

In this report, we also demonstrate the functionality of the IET by presenting baseline cases (as shown in Figure ES-2) along with case studies that explore the tool's representation of energy efficiency and fuel switching. These case studies are meant to demonstrate bounds of the tool and do not represent realistic projections of efficiency or fuel switching. Results of these case studies are presented at the national, county, and end-use levels. By benchmarking these results with the National Energy Modeling System, we find that the IET's current baseline assumptions calculate larger reductions in energy use and emissions than projections from the Annual Energy Outlook (AEO) 2017; the combination of the IET's current stock turnover and energy efficiency assumptions is the likely source of these differences.
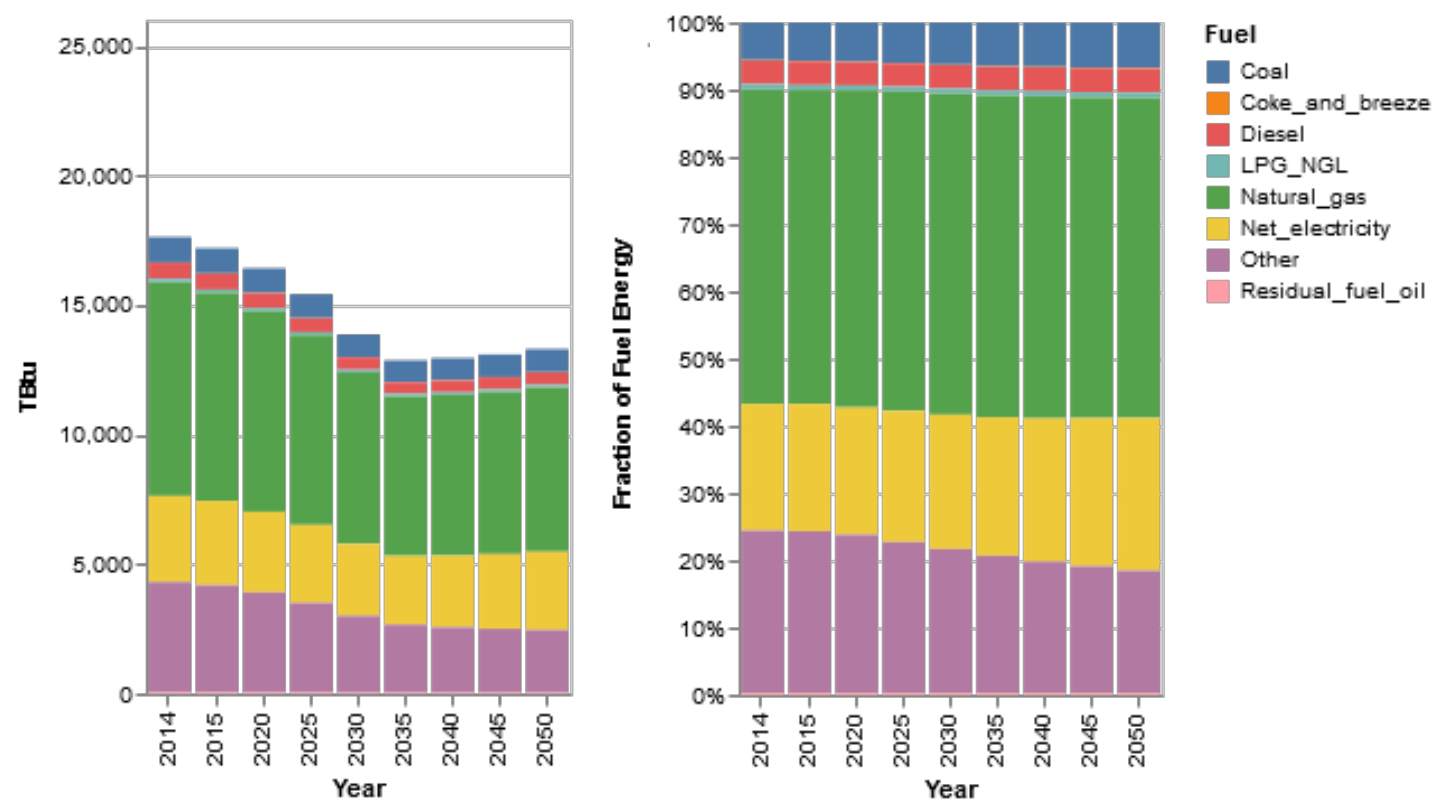

Figure ES-2. IET projected absolute and relative energy use by fuel type for baseline assumptions

\footnotetext{
${ }^{1}$ Greenhouse gas emissions are used as an input (i.e., 2014 energy use calculated from reported greenhouse gas emissions) and are an output of the IET.
} 
Based on the open-source design of both the tool and its data foundation, the IET is intended to be revised and improved over time by a community of users. We have identified several priority areas for improvement, including revisiting the baseline efficiency and stock turnover assumptions, creating a graphical user interface, and automating figure generation for scenario results, based on results of our initial set of case studies and reviewer comments.

Future improvements to the IET will build on the tool's existing strengths as a streamlined, transparent, and flexible tool for industry energy analysis. Additionally, the IET's foundational energy use data enables scenario projections at the county and specific industry level. This improved level of data resolution combined with the IET's other features offers new opportunities for analysts and policymakers to understand energy use in the U.S. industrial sector. 


\section{Table of Contents}

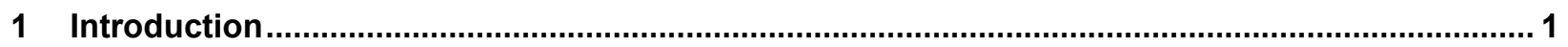

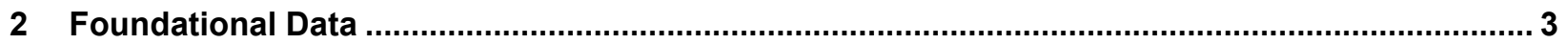

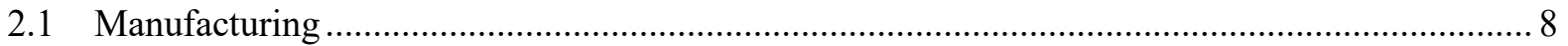

2.1.1 Facility-Level Combustion Energy and Net Electricity Calculations ........................... 10

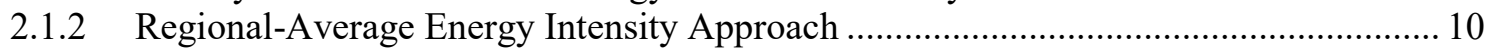

2.1.3 Combining Calculated Manufacturing Energy Use .................................................. 12

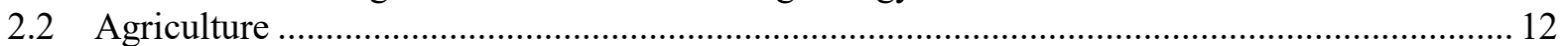

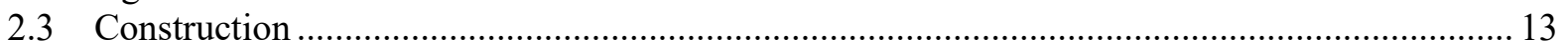

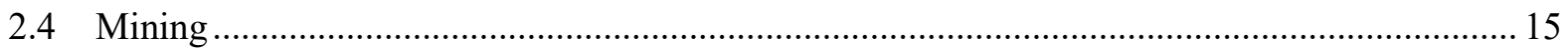

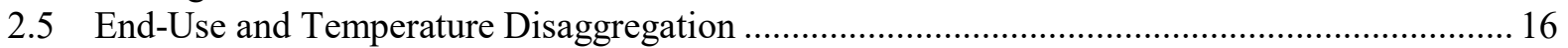

2.6 County-Level Summary and Comparisons with Publicly Available Industry Energy Data ....... 19

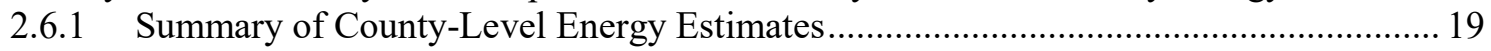

2.6.2 Comparisons with Published Industry Energy Data............................................... 23

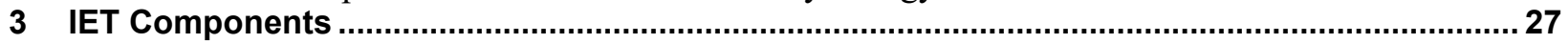

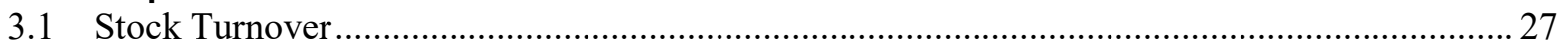

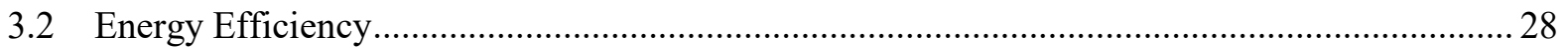

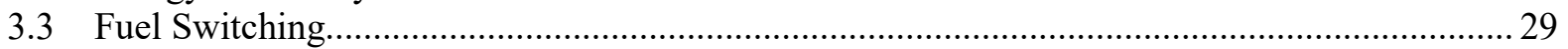

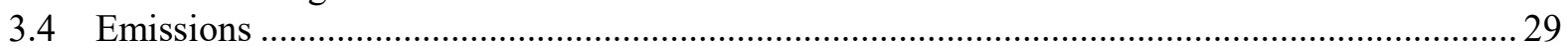

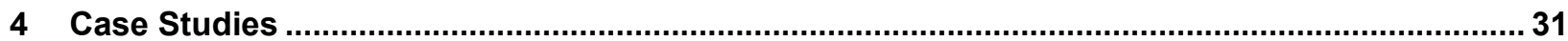

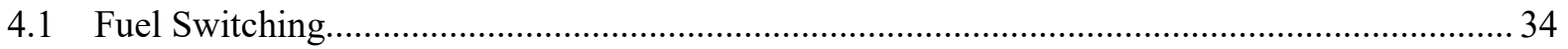

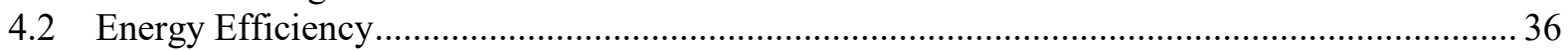

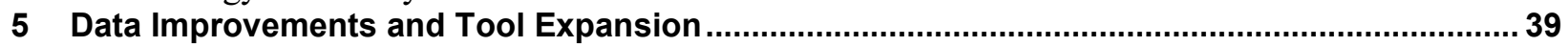

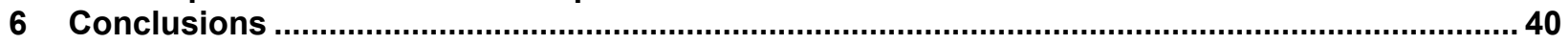

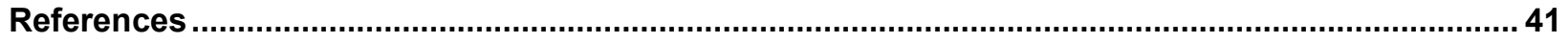

Appendix A. Dynamic Hybrid Input-Output Module ........................................................................ 46

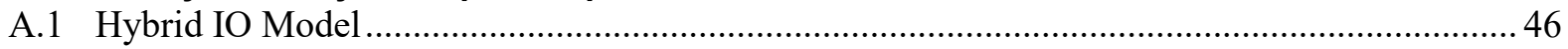

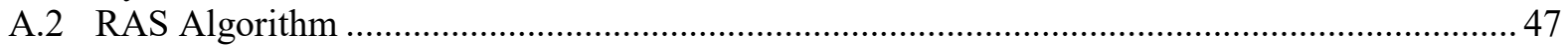

Appendix B. Comparison of IET Foundational Data and EIA State Energy Data System (SEDS) .... 50

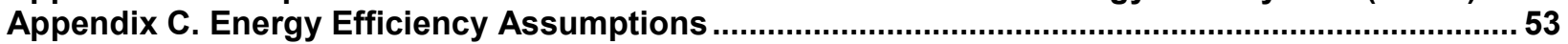




\section{List of Figures}

Figure ES-1. Estimated industrial coal use in 2014 ...........................................................................ii

Figure ES-2. IET projected absolute and relative energy use by fuel type for baseline assumptions .......... iv

Figure 1. Overview of county-level manufacturing energy use estimation ........................................... 9

Figure 2. Overview of county-level agricultural energy calculation .................................................... 13

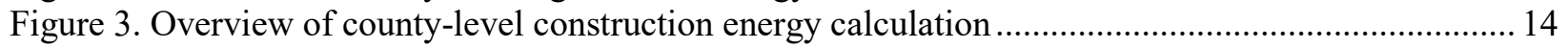

Figure 4. Overview of county-level mining energy calculation ..................................................... 16

Figure 5. Associated temperature range for 2014 county-level conventional boiler use and process

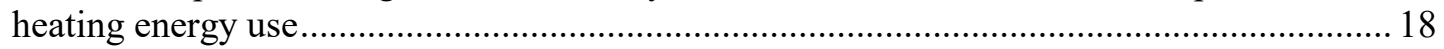

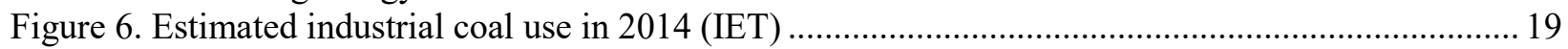

Figure 7. Estimated industrial natural gas use in 2014 (IET) .......................................................... 20

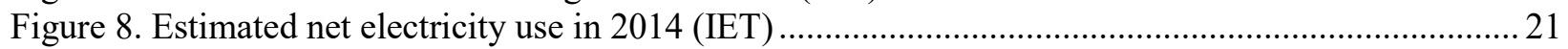

Figure 9. Estimated total energy use for iron and steel mills and ferroalloy manufacturing

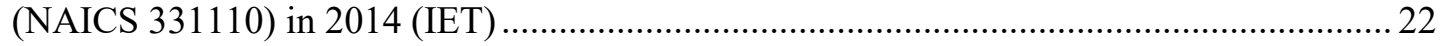

Figure 10. Estimated industrial energy use per industry employment (IET) ......................................... 23

Figure 11. National industry historical ${ }^{a}$ total greenhouse gas emissions and projections by scenario ........ 32

Figure 12. Comparison of (a) absolute and (b) relative national industry fuel energy projections from AEO 2017 and IET Baseline Stock scenario............................................................. 33

Figure 13. IET national projected coal, natural gas, and electricity use in baseline and fuel switching

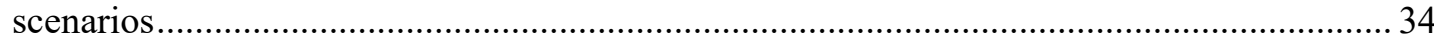

Figure 14. IET electricity generation emission factor by census region based on AEO 2017

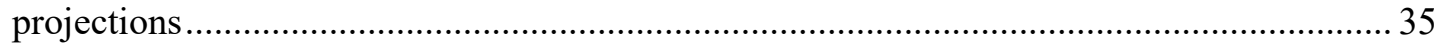

Figure 15. IET fuel switching scenario: Relative emissions savings by county in 2050 ............................ 36

Figure 16. IET baseline and energy efficiency scenario projected emissions by end use ........................ 37

Figure 17. IET energy efficiency scenario emissions savings in 2050 relative to baseline scenario........... 38

Figure 18. Relative difference between state-aggregated IET foundational data and SEDS, by fuel......... 50

\section{List of Tables}

Table 1. Sources of IET Foundational Data and Historical U.S. Industrial Energy Data........................... 5

Table 2. Summary of 2014 MECS Coverage of Manufacturing Energy Use as Fuel .............................. 7

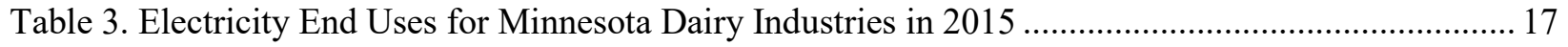

Table 4. Mapping of Mining Operational End Use to MECS End Use ................................................ 17

Table 5. Comparison of 2014 Industrial Energy Data Estimated by EIA and the IET Data Foundation ... 24 Table 6. Difference between Industry Energy Use in 2014 Reported by EIA State Energy Data System (SEDS) (EIA 2017g) and State-Level Aggregation of Data Foundation .................. 25

Table 7. Summary of Smallest and Largest Relative Differences between Data Foundation and

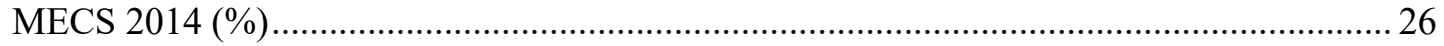

Table 8. Summary of Energy Efficiency Potentials from Industry Bandwidth Studies and TPCs............ 29

Table 9. Comparison of State-Level Aggregated IET Foundational Data and SEDS ............................. 51

Table C-1. Bandwidth Efficiency Data Assumptions by NAICS Code (Assumed Reduction in 2050

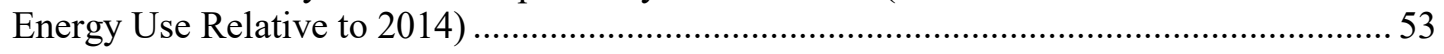




\section{Introduction}

The U.S. industrial sector is the largest energy end-use sector, and it accounts for about one-third of the country's total energy use, which has experienced only small changes in the past 15 years (EIA 2018a). Of the industrial subsectors - agriculture, construction, manufacturing, and mining-manufacturing is the most significant, accounting for over $80 \%$ of the sector total (EIA 2018b).

The goal of the Industry Energy Tool (IET) is to function as a streamlined, transparent, opensource calculator tool for U.S. industrial energy use for energy analysts and policymakers. Based on the open-source design of both the tool and its data foundation, the IET is intended to be revised and improved over time by users. This report introduces the IET to a potential user community.

The IET is composed of five basic components, one of which is the foundational energy data used by the tool and four of which are associated with operating the tool: stock turnover, energy efficiency, fuel switching, and emissions. A sixth component-a hybrid input-output (IO) model - has been developed for estimating the energy impacts of material efficiency, ${ }^{2}$ but it is not currently integrated with the tool. We discuss this component in Appendix A. We first briefly summarize the foundational data and IET tool components below and then provide detailed descriptions later in the report.

1. Foundational Data: a county-level data set for 2014 derived from several sources of publicly available data provides energy use by industry North American Industrial Classification System (NAICS) ${ }^{3}$ code, fuel type (i.e., coal, coke and breeze, natural gas, liquid petroleum gases and natural gas liquids [LPG NGL], diesel, residual fuel oil, other), end use (e.g., conventional boiler use, cogeneration, process heating, machine drive), and binned temperature requirement (where appropriate). The foundational data do not include feedstock energy (i.e., nonfuel) use such as hydrocarbon gas liquids used in producing ethylene or petroleum used in producing asphalt.

\section{IET Components}

a. Stock Turnover: Annual Energy Outlook (AEO) 2017 (EIA 2017a) value of shipments projections are used to project energy use to 2050 and as a proxy for industrial capital stock. New stock is added each year to replace existing stock that is retired and to meet any increase in value of shipments. Existing stock is assumed to retire linearly with a default lifetime of 20 years; new stock (post2014 stock) is assumed to retire linearly with a default lifetime of 30 years.

\footnotetext{
${ }^{2}$ See McMillan (2018) for a proposed analysis framework based on a dynamic hybrid input-output model.

${ }^{3}$ NAICS is a hierarchical system for categorizing the general type of economic activity of businesses. For more information, see https://www.census.gov/eos/www/naics.
} 
b. Energy Efficiency: the unit energy consumption (UEC or energy used per dollar value of shipments) of new and existing stock improves at constant annual rates based on the technical possibility curves (TPCs) used in AEO 2014 (EIA 2014). Additional efficiency improvement is implemented through a parameterization of U.S. Department of Energy (DOE) "bandwidth" studies. ${ }^{4}$

c. Fuel Switching: Fuel use in new stock is substituted for an alternate fuel at a constant annual rate defined by the user. The current assumption is switching occurs at 1:1 ratio and does not account for differences in energy efficiency. ${ }^{5}$ Additionally, this feature is currently limited to electrification.

d. Emissions: GHG emissions are calculated for projected energy use with U.S. Environmental Protection Agency (EPA) emission factors. Regional electricity emission factors are based on annual AEO 2017 Reference Case grid mix projections, with the option for user-defined changes to renewable electricity penetration.

${ }^{4}$ See “Energy Analysis, Data and Reports,” DOE, https://www.energy.gov/eere/amo/energy-analysis-data-andreports.

${ }^{5}$ This current simplification does not capture the potentially greater site energy efficiency of many electric technologies relative to combustion technologies or any potential interactions with assumed IET energy efficiency potential. 


\section{Foundational Data}

Studies of industrial energy use typically mention the sector's heterogeneity and complexity (Worrell, Ramesohl, and Boyd 2004; Fleiter, Worrell, and Eichhammer 2011; Saygin et al. 2012; Fais, Sabio, and Strachan 2016). One of the most significant impediments to analyzing and building models of U.S. industrial energy use is the lack of current disaggregated data that reflect the sector's heterogeneity and complexity. Very little about the state of industrial energy data has fundamentally changed in the 30 years since the Energy Modeling Forum (EMF) 8 recommended "serious consideration be given" to six areas of energy-related data collection (EMF 1987). ${ }^{6}$ These recommendations are worth repeating here:

1) Create an establishment-level database on energy consumption and expenditures for the manufacturing sector. The Manufacturing Energy Consumption Survey (MECS) should be expanded to allow data to be published at the 4-digit Standard Industrial Classification [SIC, replaced by NAICS] level by state and Standard Metropolitan Statistical Area.

2) The MECS should be extended to include data on costs, operating characteristics, and the utilization of other energy-related technologies.

3) A study should be undertaken on the appropriate industrial energy-related data to be collected by the public sector, with the remaining data being collected by the private sector.

4) Private groups that collect microlevel data on manufacturing production, energy consumption, etc. should be encouraged to provide public-use sets of their information for specified research projects.

5) Public-use files of government micro databases should be developed.

6) EIA and other agencies (e.g., the National Research Council, the National Academy of Engineering) should develop a source book on costs, operating characteristics, and standards to evaluate new energy-related technologies, and develop or expand existing surveys of energy consumption and technology data for the nonmanufacturing portion of the industrial sector.

To our knowledge, little progress has been made toward these six recommendations. This is particularly true for those that call for greater disaggregation of energy and operational data or for the non-manufacturing industries - agriculture, mining, and construction - whose energy data sources were described by EMF 8 as "very sketchy" (EMF 1987, iii). For example, published MECS data files provide results at the census region level and not at the state or Metropolitan Statistical Area; no public-use files of industry energy use are available from the U.S. Census Bureau (U.S. Census Bureau 2018); and non-manufacturing industries are not included in U.S. Energy Information Administration (EIA) energy end-use surveys (EIA 2018c). However, since

\footnotetext{
${ }^{6}$ One significant, additional category of data improvement not highlighted by EMF 8 is time of energy use,
} including industry operating schedules. 
EMF 8 was convened, MECS has introduced survey questions related to fuel switching, cogeneration, and energy-saving technologies (EIA 2009).

In the spirit of the data recommendations made by EMF 8, we have made a significant step in improving the state of industrial energy data by developing a county-level energy data set whose basis is facility-level energy data derived from greenhouse gas (GHG) emissions reported to the EPA. ${ }^{7}$ We consider the IET foundational data to be a new and continuously-improving bottomup source of industrial energy data.

Table 1 summarizes the publicly available sources of historical data for and related to U.S. industrial energy use. The table also indicates whether these data sources are used to construct the IET's foundational data. Although these data sources identify how much energy was used by an industry in each location, only MECS provides information on how the energy was used (i.e., energy end uses). MECS identifies 13 end-use categories; we are not aware of sources of end-use data for agriculture, construction, and mining that are similarly consistent, detailed, and complete.

\footnotetext{
${ }^{7}$ For description of the methodology used to construct this data set, see McMillan et al. 2016. For the Python code implementation of this methodology, see "Industrial Heat Demand Analysis," Jupyter notebook at https://github.com/NREL/Industrial-Heat-Demand-Analysis.
} 
Table 1. Sources of IET Foundational Data and Historical U.S. Industrial Energy Data

\begin{tabular}{|c|c|c|c|c|c|c|}
\hline Data Source & Agency & Units & Frequency & $\begin{array}{l}\text { Extent of Industry } \\
\text { Disaggregation }\end{array}$ & $\begin{array}{l}\text { Extent of Geographic } \\
\text { Disaggregation }\end{array}$ & $\begin{array}{l}\text { Used by } \\
\text { the IET }\end{array}$ \\
\hline $\begin{array}{l}\text { Monthly Energy } \\
\text { Reviewa }^{a}\end{array}$ & EIA & Energy & Monthly & Total industry & National & No \\
\hline $\begin{array}{l}\text { State Energy } \\
\text { Data System } \\
\text { (SEDS) }^{\mathrm{b}}\end{array}$ & EIA & Energy & Annual & Total industry & State & No \\
\hline MECSc & EIA & Energy & Quadrennial & $\begin{array}{l}\text { Manufacturing; up } \\
\text { to six-digit NAICS } \\
\text { code and by } \\
\text { end use }\end{array}$ & Census Region & Yes \\
\hline Form EIA-923 & EIA & $\begin{array}{l}\text { Energy (electricity } \\
\text { only) }\end{array}$ & Annual & $\begin{array}{l}\text { Up to six-digit } \\
\text { NAICS }\end{array}$ & Facility & Yes \\
\hline $\begin{array}{l}\text { Census of } \\
\text { Agriculture }^{\mathrm{e}}\end{array}$ & $\begin{array}{l}\text { U.S. } \\
\text { Department of } \\
\text { Agriculture } \\
\text { (USDA) }\end{array}$ & Expenditures & Quinquennial & $\begin{array}{l}\text { Agriculture; up } \\
\text { to four-digit } \\
\text { NAICS code }\end{array}$ & County & Yes \\
\hline $\begin{array}{l}\text { Agriculture } \\
\text { Survey }\end{array}$ & USDA & Expenditures & Annual & Total agriculture & State & Yes \\
\hline $\begin{array}{l}\text { Economic } \\
\text { Census }^{9}\end{array}$ & $\begin{array}{l}\text { Census } \\
\text { Bureau }\end{array}$ & $\begin{array}{l}\text { Expenditures, } \\
\text { some energy units } \\
\text { for mining }\end{array}$ & Quinquennial & $\begin{array}{l}\text { Construction, } \\
\text { manufacturing, and } \\
\text { mining; up to six- } \\
\text { digit NAICS }\end{array}$ & State & Yes \\
\hline $\begin{array}{l}\text { Annual Survey of } \\
\text { Manufacturers }^{\mathrm{h}}\end{array}$ & $\begin{array}{l}\text { Census } \\
\text { Bureau }\end{array}$ & $\begin{array}{l}\text { Expenditures; } \\
\text { energy units } \\
\text { for generated } \\
\text { electricity }\end{array}$ & Annual & $\begin{array}{l}\text { Manufacturing; up } \\
\text { to six-digit NAICS }\end{array}$ & $\begin{array}{l}\text { National for six- } \\
\text { digit NAICs; state } \\
\text { for two-digit NAICS }\end{array}$ & No \\
\hline
\end{tabular}




\begin{tabular}{|l|l|l|l|l|l|l|}
\hline Data Source & Agency & Units & Frequency & $\begin{array}{l}\text { Extent of Industry } \\
\text { Disaggregation }\end{array}$ & $\begin{array}{l}\text { Extent of Geographic } \\
\text { Disaggregation }\end{array}$ & $\begin{array}{l}\text { Used by } \\
\text { the IET }\end{array}$ \\
\hline CBPi & $\begin{array}{l}\text { Census } \\
\text { Bureau }\end{array}$ & $\begin{array}{l}\text { Establishment } \\
\text { counts }\end{array}$ & Annual & $\begin{array}{l}\text { Up to six-digit } \\
\text { NAICS }\end{array}$ & County \\
\hline GHGRPj & EPA & $\begin{array}{l}\text { Emissions, energy } \\
\text { in some cases }\end{array}$ & Annual & $\begin{array}{l}\text { Up to six-digit } \\
\text { NAICS }\end{array}$ & Facility \\
\hline
\end{tabular}

a "Total Energy: Monthly Energy Review," EIA, https://www.eia.gov/totalenergy/data/monthly/index.php

b "U.S. States Profile: State Profiles and Energy Estimates: About SEDS," EIA, https://www.eia.gov/state/seds/

c "Manufacturing Energy Consumption Survey (MECS)," EIA, https://www.eia.gov/consumption/manufacturing/index.php

d "Electricity: Form EIA-923 Detailed Data with Previous Form Data (EIA-906/920)," EIA, https://www.eia.gov/electricity/data/eia923/

e "USDA Census of Agriculture," USDA, https://agcensus.usda.gov/

f "USDA National Agricultural Statistics Service: Quick Stats," USDA, https://quickstats.nass.usda.gov/

g "Economic Census," U.S. Census Bureau, https://www.census.gov/programs-surveys/economic-census.html

h "Annual Survey of Manufactures (ASM)," U.S. Census Bureau, https://www.census.gov/programs-surveys/asm.html

i "County Business Patterns (CBP)," U.S. Census Bureau, https://www.census.gov/programs-surveys/cbp.html

j "Greenhouse Gas Customized Search,” EPA, https://www.epa.gov/enviro/greenhouse-gas-customized-search 
Today - as was the case when EMF 8 convened - the most well-developed industrial energy data exist for manufacturing industries, which are responsible for about $80 \%$ of U.S. industry energy use. MECS is the main source of manufacturing energy data, which EIA publishes every four years. ${ }^{8}$ The survey is conducted by EIA, which contracts the U.S. Census Bureau to collect data from about 15,000 manufacturing establishments (EIA 2002). Microdata are available, but the U.S. Census Bureau limits researcher access and use (U.S. Bureau of the Census 2009). MECS also withholds data and limits its reporting resolution to avoid identifying specific companies.

To get a sense of the constraints for characterizing manufacturing energy use, we break down MECS coverage into dimensions of operational characteristics (represented by NAICS code, fuel type disaggregation, and end-use disaggregation) and geography, as summarized in Table 2. Of the 14,903 trillion British thermal units (TBtu) of fuel energy reported by U.S. manufacturing establishments in 2014, about $75 \%$ is represented by six-digit NAICS codes, fuel type, and census region. We note that the portion of total energy use for each census region that is disaggregated by NAICS code and fuel type varies, with a range from $63 \%$ in the Northeast to $82 \%$ in the South. About $41 \%$ of manufacturing energy use is covered at the six-digit NAICS code and fuel type at the national scale when disaggregated by end-use category; MECS currently does not report energy by end-use category and by NAICS code at the census region, which would be useful for revealing regional differences in how energy is used within industries.

Table 2. Summary of 2014 MECS Coverage of Manufacturing Energy Use as Fuel

\begin{tabular}{|l|c|c|}
\hline $\begin{array}{l}\text { Operational/Geographic } \\
\text { Coverage }\end{array}$ & National & Census Region \\
\hline six-digit NAICS & $76 \%$ & $75 \%^{\mathrm{a}}$ \\
\hline six-digit NAICS, fuel type & $75 \%$ & $75 \%^{\mathrm{a}}$ \\
\hline six-digit NAICS, fuel type, end use & $41 \%$ & $0 \%$ \\
\hline
\end{tabular}

a The coverage of regional total energy use varies within each census region, from $63 \%$ in the Northeast, $66 \%$ in the Midwest, $72 \%$ in the West, to $82 \%$ in the South.

The IET's foundational data, as well as the calculations behind their derivation, are publicly available. ${ }^{9}$ We invite energy analysts, computer scientists, and other researchers and practitioners to push the state of industrial energy data forward and contribute improvements to our initial methods. The following sections detail the assumptions and calculations used to construct the IET's foundational data and we compare the results to existing EIA sources of industrial energy data to benchmark its representation of industrial energy use.

\footnotetext{
${ }^{8}$ MECS was conducted every three years from 1985 through 1994 . Since then, it has been conducted every four years.

${ }^{9}$ Data are available from the NREL Data Catalog (https://doi.org/10.7799/1481899). The calculations used in their construction are available at https://github.com/NREL/Industry-Energy-Tool.
} 


\subsection{Manufacturing}

The method used by the IET to calculate county-level energy use for manufacturing industries is based on (1) county counts of manufacturing establishments by industry and employment size from Census County Business Patterns (CBP) data (U.S. Census Bureau 2016) and (2) either facility-level energy data or regional-average energy data. Facility-level estimates of energy use are calculated for large energy-users using EPA Greenhouse Gas Reporting Program (GHGRP) emissions data (EPA 2017) and electricity use reported by industry generators above $1 \mathrm{MW}$ from Form EIA-923 (EIA 2017b). ${ }^{10}$ Regional-average energy intensity values (energy per establishment) are estimated by NAICS code, fuel type, and employment size class using data derived from 2010 MECS (EIA 2013) ${ }^{11}$ and iterative proportional fitting, described in Section 2.1.2 below.

In general, the method first identifies the count of GHGRP- and Form EIA-923-reporting facilities by county and then subtracts their number from the CBP establishment counts. Energy data for the GHGRP reporters are estimated using reported emissions data and Form EIA-923 electricity data. Energy use for the remaining establishments is calculated based on NAICS code, fuel type, and employment size class using the derived regional-average energy intensity values. ${ }^{12}$ These aspects of the approach are summarized in Figure 1 and described in detail below.

\footnotetext{
10 Not all GHGRP reporters have electricity generation or cogeneration units with more 1 MW of capacity. Net electricity use for the GHGRP-reporting facilities that do not report with Form EIA-923 is estimated using regional-average net electricity intensity.

112014 MECS data were not published when the IET's foundational data were developed. Updating the calculations to the most recent MECS has been identified for future work.

12 The employment size classes of GHGRP-reporting facilities are not provided in GHGRP data. We assume the largest employment size class for GHGRP-reporting facilities when correcting CBP establishment counts by county. However, we take a conservative approach and do not adjust CBP establishment counts when deriving regional-average energy intensity values. This may lead to overestimating energy intensity and the resulting county energy values. Future work could examine the sensitivity.
} 


\section{Average Intensity Approach (GHGRP Non-Reporters)}

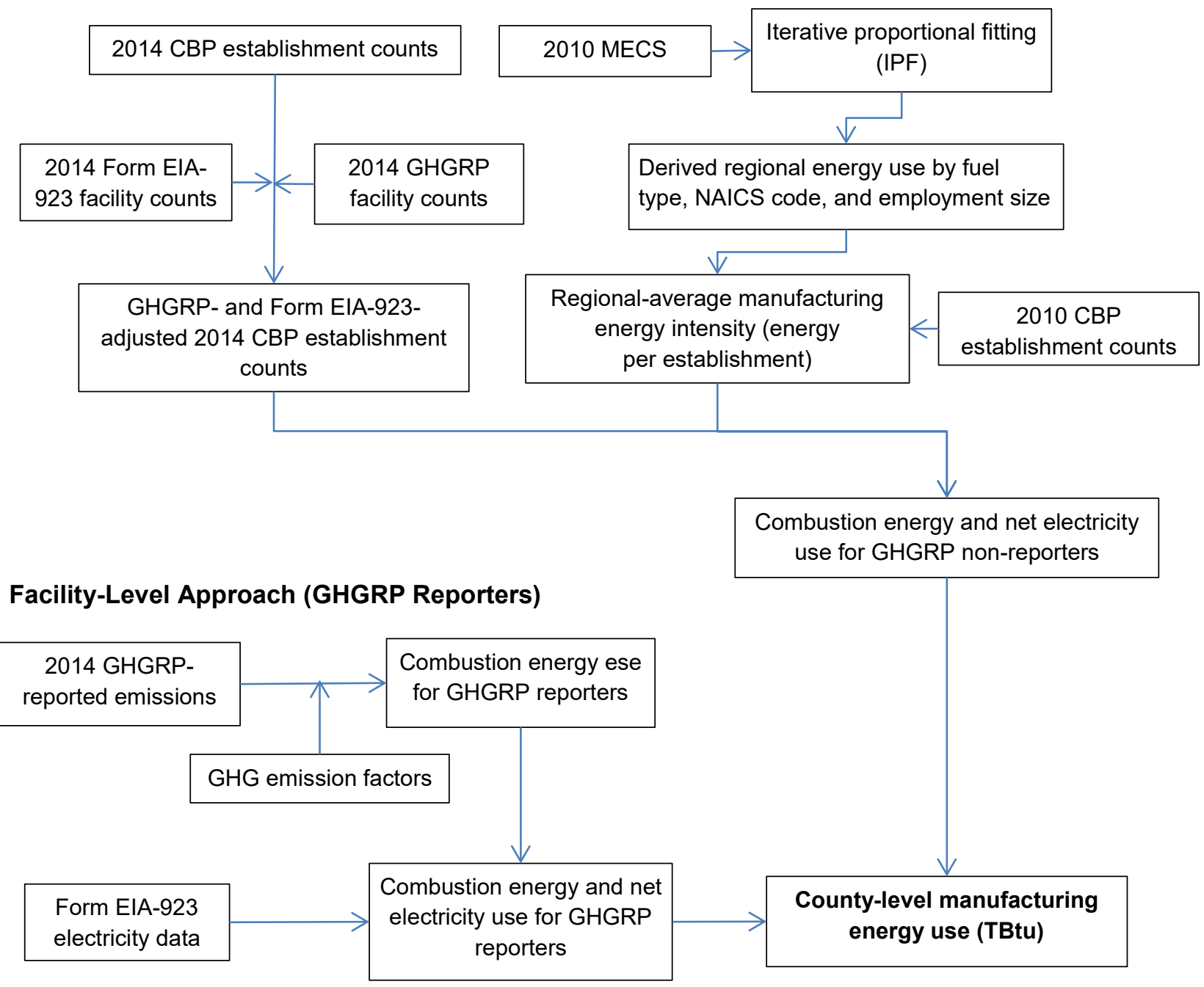

Figure 1. Overview of county-level manufacturing energy use estimation 


\subsubsection{Facility-Level Combustion Energy and Net Electricity Calculations}

Facilities with annual GHG emissions that exceed 25,000 metric tons carbon dioxide-equivalent (MMTCO2e) are required to report emissions under the GHGRP (Mandatory Greenhouse Gas Reporting 2009). GHG emissions reported under Subpart C General Stationary Combustion Sources and Subpart D Electricity Generation ${ }^{13}$ are used with average GHG emission factors by fuel type (EPA 2018) ${ }^{14}$ to back-calculate facility combustion energy use for relevant manufacturing, mining, and agriculture facilities. ${ }^{15}$

A crosswalk table of electricity data is created based on facility name and location for facilities reporting to the GHGRP and Form EIA-923. Note that Form EIA-923 provides electricity use data only for industrial facilities with onsite generation - cogenerating or non-cogeneratingexceeding $1 \mathrm{MW}$. Net electricity use for these facilities is calculated as the sum of incoming electricity and generation from noncombustible renewable sources, less the sum of retail sales, sales for resale (i.e., wholesale sales), tolling agreements, and all other outgoing electricity. The net electricity use for GHGRP-reporting facilities that are not listed on Form EIA-923 is calculated using regional-average net electricity intensities, which are described in the next section.

\subsubsection{Regional-Average Energy Intensity Approach}

Regional-average energy intensities per manufacturing establishment are used to calculate the combustion energy use of establishments that do not report under the GHGRP. Likewise, regional-average net electricity use intensities are calculated to estimate electricity use of establishments that do not report to EIA Form-923. This section describes the process of first deriving average energy values by census region, fuel type, NAICS code, and employment size class using IPF and 2010 MECS data. CBP establishment counts by NAICS code and employment size class are then used to calculated energy intensity values. Finally, these perestablishment energy intensities are multiplied by adjusted CBP establishment counts to estimate the energy use of facilities that do not report under the GHGRP or Form EIA-923. This final step involves portioning the number of CBP-reported manufacturing establishments into GHGRPreporting and GHGRP non-reporting facilities within a given county to avoid double-counting energy use. ${ }^{16}$

\footnotetext{
${ }^{13}$ Utilities and other non-industrial reporters are excluded from the energy calculations based on Subpart D emissions.

${ }^{14}$ Using average emission factors and not fuel-specific carbon content data does introduce uncertainty into our facility-level energy calculations. We have not yet quantified this uncertainty.

${ }^{15}$ Note that energy calculations based on GHGRP data do not include electricity use. For details, refer to the method description in McMillan et al. (2016). This method does undercount energy use by cement plants that use continuous emissions monitoring systems (CEMS). Typically, the calculation method would calculate energy use by facilities with CEMS, but as of September 2017 the GHGRP reporting tool continues to record emissions under the incorrect subpart (email communication with Sydnie Lieb, EPA, December 7, 2016).

${ }^{16}$ In 2014, 307 manufacturing facilities reported to the GHGRP under Subpart C General Stationary Combustion Sources that are not matched to a CBP county and NAICS code. We assumed that the GHGRP-reported NAICS codes for these facilities are correct and that they are not captured in the CBP data. This assumption may result in double-counting of energy use in counties where the GHGRP-reported NAICS codes are incorrect.
} 
We apply iterative proportional fitting (IPF) ${ }^{17}$ to 2010 MECS data (Table 3.2 and Table 3.3) to derive energy use by census region, fuel type, ${ }^{18}$ NAICS code, ${ }^{19}$ and employment size class. Facility-average combustion energy and electricity use intensities are then calculated by dividing the IPF energy results by 2010 CBP establishment counts. Note again this method does not adjust MECS energy data for combustion energy use calculated for GHGRP reporters.

Regional-average energy intensity values are applied to adjusted 2014 CBP establishment counts by NAICS code and employment size class. To avoid double-counting energy use estimated with the facility-level approach, the CBP establishment counts are partitioned into groups based on whether establishments report under the GHGRP or EIA Form-923. This partitioning involves matching GHGRP facilities that reported in 2014 to 2014 CBP establishment counts based on their reported county and state Federal Information Processing Standards (FIPS) codes and primary and secondary NAICS code. A GHGRP-reporting facility that is matched to a county and NAICS code is assumed to be represented by the largest employment size class reported by the CBP. The adjusted 2014 CBP establishment counts are calculated by subtracting the number of GHGRP-reporting facilities by county and NAICS code by descending employment size class.

A separate partitioning approach is used to calculate manufacturing electricity use. The procedure follows the general approach described above except that it uses county-level establishment counts of the subset of GHGRP-reporting facilities that also report electricity data with Form EIA-923.

County-level combustion energy use for non-GHGRP reporters is then calculated by multiplying the combustion fuel intensity by the adjusted 2014 CBP establishment count. County-level electricity use for facilities that are not GHGRP reporters and do not report electricity data with Form EIA-923 is calculated by multiplying the facility-average net electricity ${ }^{20}$ intensity and 2014 CBP establishment counts that have been adjusted for GHGRP and Form EIA-923reporters.

\footnotetext{
${ }^{17}$ IPF is an algorithm for updating a table of values based on specific constraints; in the two-dimensional case, these constraints are row and column sums. We use IPF to estimate MECS data not reported publicly based on a combination of two public data tables.

${ }^{18}$ Combustion energy use is calculated according to MECS fuel type: net electricity, natural gas, residual fuel oil, diesel, liquid petroleum gas-natural gas liquids (LPG-NGL), coal, coke and breeze, and "other."

${ }^{19}$ MECS does not report energy use for all six-digit manufacturing NAICS codes, but all CBP establishment counts are reported at the six-digit level. CBP data are aggregated to match the level of detail provided by MECS. As a result, energy intensities may be calculated at the three-digit NAICS code level and applied to establishment counts at the six-digit NAICS code level.

${ }^{20}$ EIA defines net electricity as the sum of purchases, transfers in, and generation from noncombustible renewable resources, minus quantities sold and transferred out. Electricity inputs from onsite cogeneration and generation from combustible fuels are not included because their energy value is already captured by the fuel use data. Conversely, EIA defines net demand for electricity as the sum of purchases, transfers in, and total onsite electricity generation, minus sales and transfers offsite. Net demand for electricity is the total amount of electricity used by establishments (EIA 2017c).
} 


\subsubsection{Combining Calculated Manufacturing Energy Use}

Combustion energy use calculated using the facility-level approach is aggregated by MECS fuel type, and state and county FIPS and combined with combustion energy and net electricity use calculated using the regional-average approach by state and county FIPS codes and six-digit NAICS code. These results are then combined with net electricity use obtained from Form EIA923 by state and county FIPS codes and six-digit NAICS code.

\subsection{Agriculture}

The overall approach to calculate county-level agriculture energy use is separated into liquid fuels (i.e., diesel, LPG, gasoline, and "other") and electricity. The calculation process is summarized in Figure 2. Liquid fuel use is estimated by first calculating the liquid fuel fraction of total fuel and lubricants expenses by region from 2014 USDA agricultural survey data (USDA National Agricultural Statistics Service 2018). These fractions are then multiplied by the statelevel 2012 total fuel and lubricants expenses by four- to six-digit NAICS code from the Census of Agriculture (United States Department of Agriculture 2017) and adjusted based on the ratio of 2014:2012 fuel expenses by region.

State-level electricity expenses by four- and six-digit NAICS code are calculated by multiplying 2014 state-level electricity expenses (USDA Economic Research Service 2018) by the state-level fraction of 2012 utility expenditures by four- to six-digit NAICS code from the 2012 Census of Agriculture.

Liquid fuel and electricity expenditures are converted into energy units using 2014 EIA stateand regional-level energy prices (EIA 2017d, 2017e) ${ }^{21}$ State energy totals are then apportioned to the county-level using farm counts by four- to six-digit NAICS code from the 2012 Census of Agriculture.

${ }^{21}$ These final calculations also involve using energy density unit conversion (e.g., diesel prices are provided in \$/gallon and the energy density of diesel is assumed to be 5.774 million Btu/gallon). 


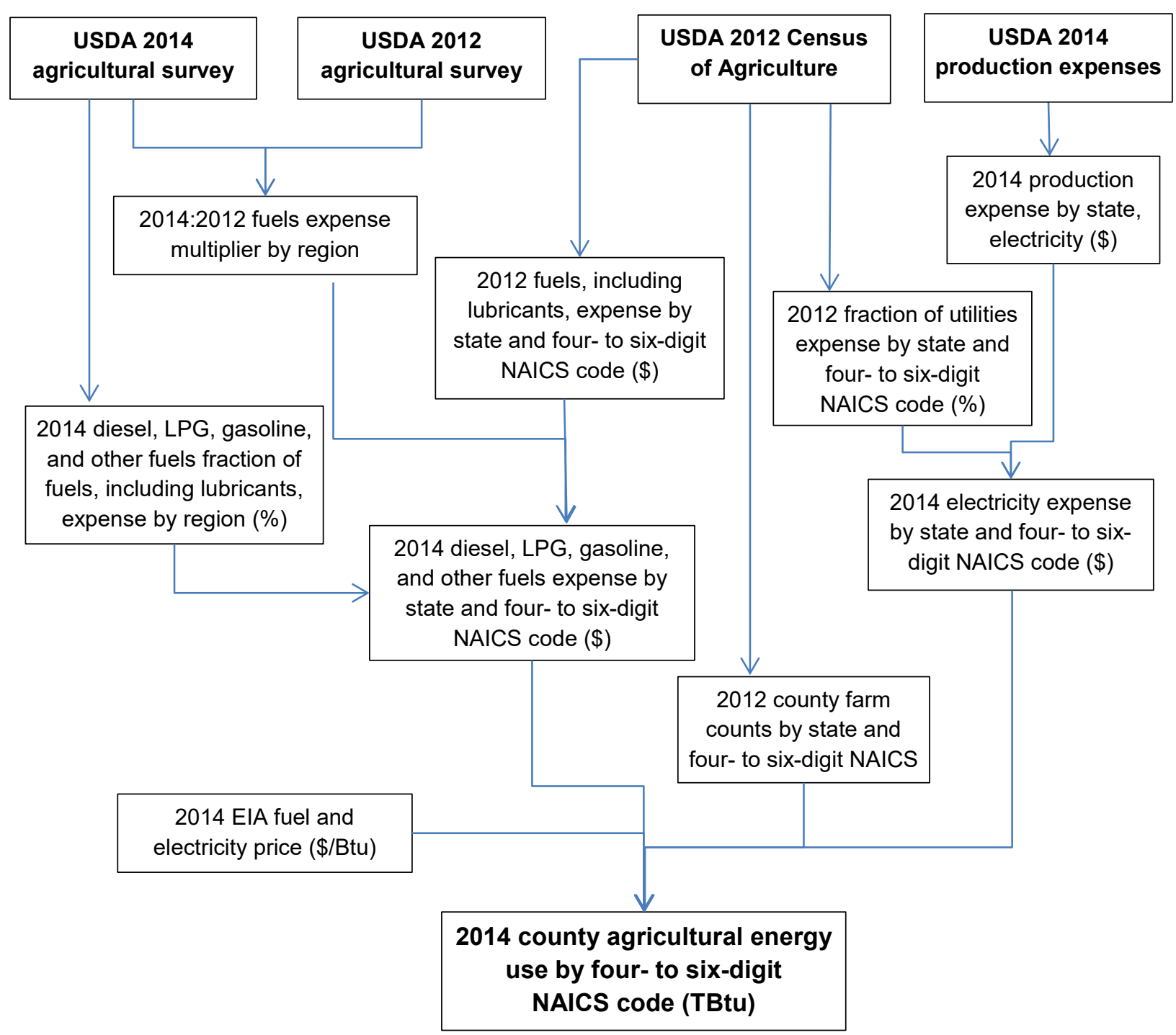

Figure 2. Overview of county-level agricultural energy calculation

\subsection{Construction}

The overall calculation approach - summarized in Figure 3-is to first estimate state-level construction energy use derived from 2012 Economic Census data and to then allocate to the county-level using CBP establishment counts. State-level calculations begin by using IPF to derive "Cost of materials, parts, supplies, electricity, and fuels $(\$ 1,000)$ " by three-digit NAICS code, employment size class, and state from the 2012 Economic Census. The fuel cost fraction of "Cost of materials, parts, supplies, electricity, and fuels $(\$ 1,000)$ ",22 is then calculated for each

\footnotetext{
22 Data for "Cost of gasoline and diesel fuel $(\$ 1,000)$ " is assumed to represent diesel fuel only, based on zero motor gasoline use, as reported in AEO 2017 projections for construction sector (EIA 2017f).
} 
fuel type by state and three-digit NAICS. The energy associated with asphalt use is not captured in the calculation. "Other fuels and lubricants" are assumed to be LPG.

The fuel cost fraction is multiplied by the results of the IPF to calculate fuel type expenses by three-digit NAICS code, employment size class, and state. These fuel type expenses are then multiplied by EIA 2012 state- or Petroleum Administration for Defense District-level fuel price per million Btu. The compound annual growth rate from 2012 to 2014 of construction GDP by state is then used to calculate energy values in 2014. Energy values are then allocated to the county-level using CBP establishment counts by three-digit NAICS code and employment size class.

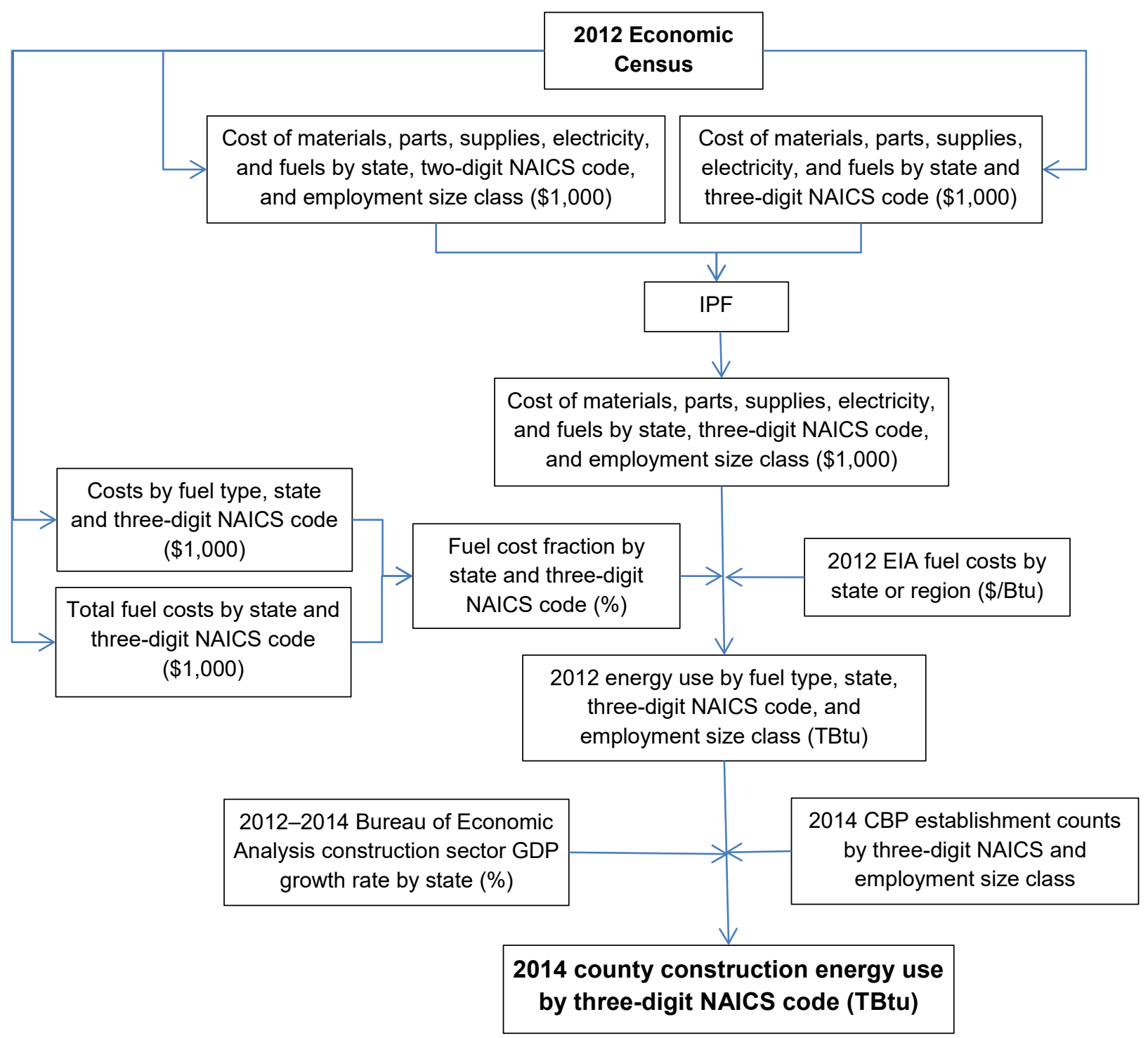

Figure 3. Overview of county-level construction energy calculation 


\subsection{Mining}

As with the manufacturing energy calculations, mining energy use is calculated using a facilitylevel approach and an average intensity approach. Facility-level detail for combustion fuels is provided by GHGRP data for large emitters; facility-level detail for net electricity use is provided by the EIA in Form EIA-923 for covered establishments. National-average energy intensities are calculated by fuel type and six-digit NAICS code from 2012 Economic Census data-adjusted CBP establishment counts by county and six-digit NAICS code. The two approaches are summarized in Figure 4 (page 16).

The 2012 Economic Census data provide detailed national-level delivered cost data by fuel type by six-digit NAICS code; use of certain fuels in physical quantities is also provided for several mining industries. Cost data that had been withheld were estimated based on total fuel costs, where appropriate. As a result, the fuel cost data by fuel type capture over $95 \%$ of the total delivered fuel costs for most of the mining industries. Fuel use in energy units is then calculated by multiplying fuel cost data by their 2012 national-average price and heat of combustion value. Data on electricity purchased for heat and power (in 1,000 kWh) is provided separately by the 2012 Economic Census but is likewise available at the six-digit NAICS level for the United States. Fuel and electricity use in 2014 is calculated by scaling 2012 values using the 2012-2014 change in physical production data from USGS mineral and commodity data (USGS 2016) by six-digit NAICS code.

National-level 2014 energy use data are allocated to the county-level using 2014 CBP establishment counts data by six-digit NAICS code. These establishment counts are adjusted by subtracting the number of GHGRP-reporting facilities in the mining sector, as the fuel use for these facilities is calculated separately from reported emissions. County-level fuel and electricity estimates by six-digit NAICS code are then calculated by multiplying the county fraction of total mining establishment count by the estimated national-level energy use value. These values are then combined with the results of the GHGRP-based combustion fuel and EIA Form-923 electricity calculations for mining industries using the method described in Section 2.1. 
Average Intensity Approach (GHGRP Non-Reporters)

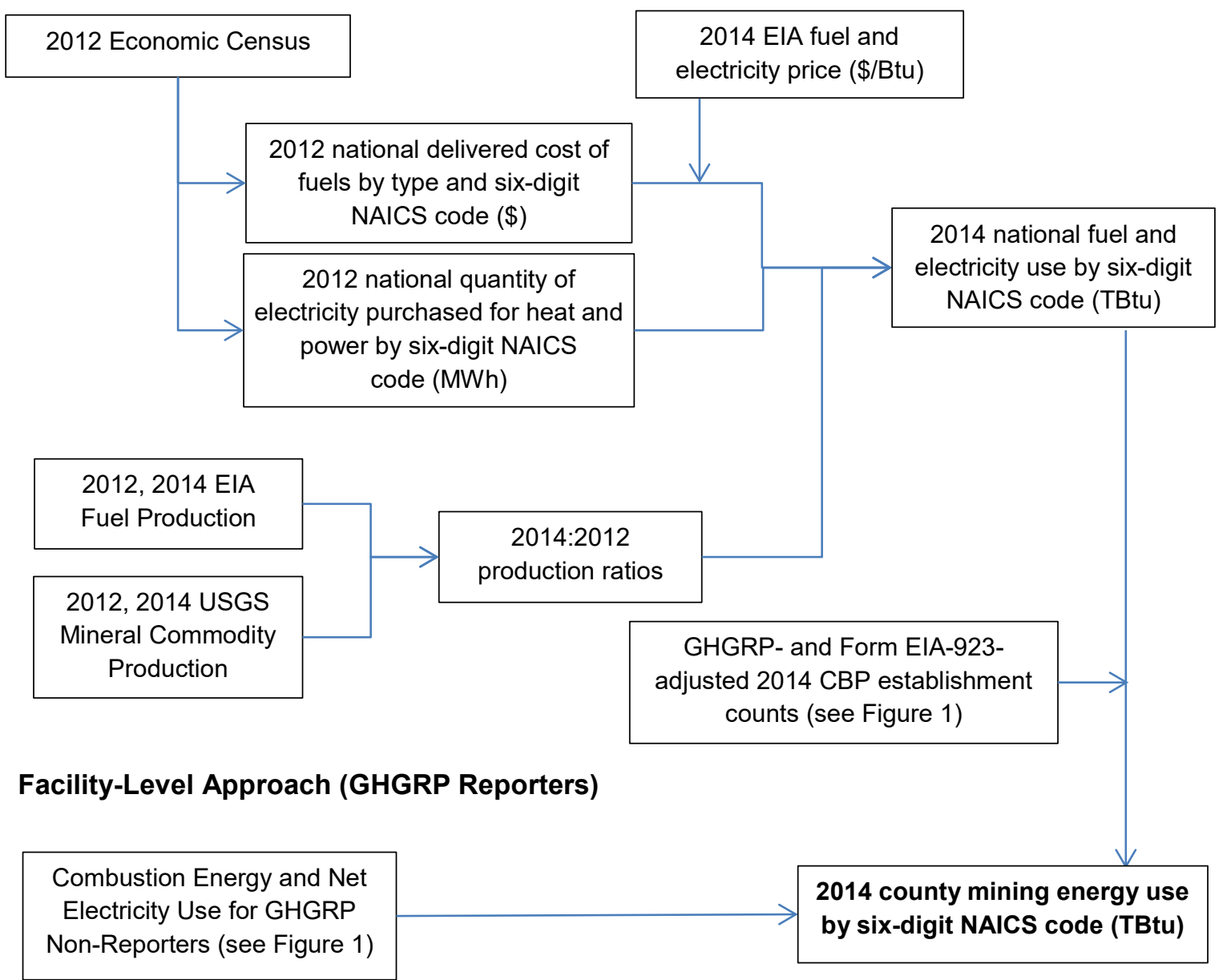

Figure 4. Overview of county-level mining energy calculation

\subsection{End-Use and Temperature Disaggregation}

The calculated county-level energy use by industry and fuel type described above are further disaggregated into end uses based on MECS categories. ${ }^{23}$ End-use disaggregation is most complete for the manufacturing industries because of the end-use data available from MECS. ${ }^{24}$ Information on energy end uses for agriculture, construction, and mining was much more difficult to find. The data sources we did find in the literature were often many years old. As described below, we were unable to disaggregate construction industry end uses because of

\footnotetext{
${ }^{23}$ Conventional boiler use, CHP and/or cogeneration process, process heating, process cooling and refrigeration, machine drive, electro-chemical processes, other process use, facility HVAC, facility lighting, other facility support, onsite transportation, conventional electricity generation, and other nonprocess use.

${ }^{24}$ Although MECS does provide end use data for all manufacturing NAICS codes, many industries are not characterized beyond the three-digit NAICS code. We assigned end uses to portions of uncharacterized end use data following the approach of Fox, Sutter, and Tester (2011).
} 
a lack of appropriate end-use data. As a result, the construction industry is excluded from the IET scenario projections.

We found several sources of end-use data for different agricultural industries, including statespecific detail (The Minnesota Project 2015; E. Brown and Elliott 2005; Ludington and Johnson 2003). For example, major end uses of electricity in the dairy industry are shown in Table 3

Table 3. Electricity End Uses for Minnesota Dairy Industries in 2015

\begin{tabular}{|l|c|}
\hline End Use & Portion of Energy Use (\%) \\
\hline Water heating & 22.0 \\
\hline Milk cooling & 17.6 \\
\hline Ventilation & 18.8 \\
\hline Vacuum pumps & 14.6 \\
\hline Lighting & 12.9 \\
\hline Miscellaneous & 14.1 \\
\hline
\end{tabular}

The Minnesota Project (2015)

For the mining sector we used end-use data from the DOE's mining bandwidth study (DOE 2007). As with the sources of agricultural end-use data, it was necessary to map the reported mining end uses to our MECS-designated categories. This mapping is shown in Table 4.

Table 4. Mapping of Mining Operational End Use to MECS End Use

\begin{tabular}{|l|l|l|}
\hline Mining End Use & MECS End Use & Fuel Type (\% of total) \\
\hline Drilling & Machine drive & Electricity (50), diesel (50) \\
\hline Blasting & Other process use & Other \\
\hline Digging & Machine drive & Electricity (50), diesel (50) \\
\hline Ventilation & Other process use & Electricity (100) \\
\hline Dewatering & Other process use & Electricity (100) \\
\hline Materials handling: electric equipment & Machine Drive & Electricity (100) \\
\hline Materials handling: diesel equipment & Machine Drive & Diesel (100) \\
\hline Beneficiation & Other process use & Electricity (50), diesel (50) \\
\hline Ancillary & Other non-process use & Electricity (75), diesel (25) \\
\hline
\end{tabular}

For construction industries, our literature review did find sources that disaggregated energy use by the building and non-building sectors, but we were unable to use this information without additional detail on the types of fuels used (Stein et al. 1980; Hannon, Stein, Segal, and Serber 1977; Hannon, Stein, Segal, Serber, et al. 1977). As a result, we did not disaggregate energy use in the construction industries. 
Conventional boiler use, $\mathrm{CHP}$ and/or generation, and process heating end uses in manufacturing industries are further disaggregated by operating temperature range. We first match operating temperature data from Brown et al. (1997) — included in the NREL Data Catalog 25 — to the county-level data set by industry and end use. Not all industries appear in the reference data. As a result, about $70 \%$ and $97 \%$ of the 2014 county-level energy use for conventional boiler use and process heating, respectively, has associated temperature data. Temperatures are then aggregated into five bins: $<100^{\circ} \mathrm{C}, 100-249^{\circ} \mathrm{C}, 250-399^{\circ} \mathrm{C}, 400-999^{\circ} \mathrm{C}$, and $>1,000^{\circ} \mathrm{C}$. The portion of conventional boiler use and process heating energy use represented by each temperature band is summarized in Figure 5. A more detailed disaggregation of process temperature data-including industry and narrower temperature bins - is possible using the IET data. Over half of process heating energy use is associated with temperatures of $400^{\circ} \mathrm{C}$ and above. Conversely, nearly all conventional boiler energy end use is associated with temperatures below $400^{\circ} \mathrm{C}$.

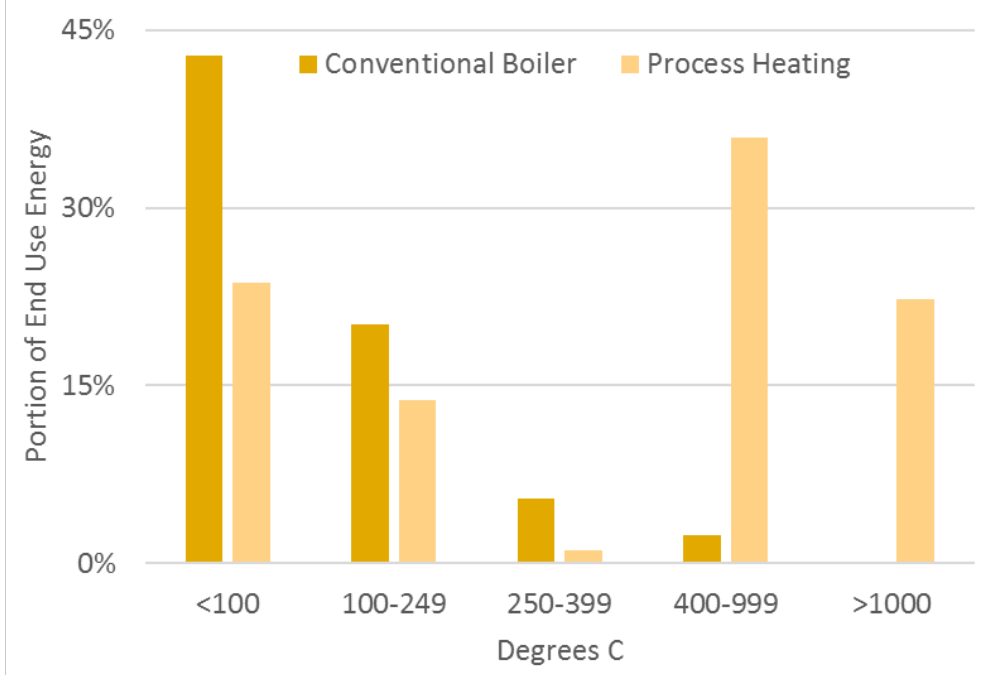

Figure 5. Associated temperature range for 2014 county-level conventional boiler use and process heating energy use

25 See https://doi.org/10.7799/1481899. 


\subsection{County-Level Summary and Comparisons with Publicly Available Industry Energy Data}

The IET's foundational data are available from the NREL Data Catalog ${ }^{26}$ and are either disaggregated by end use or are not. In this section, we provide a high-level overview of estimated county-level energy use by mapping individual fuels, a single industry, and energy intensity per industry employment. We also compare our estimates with published sources of industrial energy data at the national, state, industry, and fuel type levels.

\subsubsection{Summary of County-Level Energy Estimates}

We estimate Macon County, Illinois, is the largest industrial coal-using county in the United States. Wet corn milling facilities (NAICS 311221) in the county are responsible for nearly $90 \%$ of its coal use. Alumina refining and primary aluminum production (NAICS 331313) drives coal use in the second-largest county, Warrick County, Indiana. Estimated coal use for these counties and the rest of the United States is shown in Figure 6.

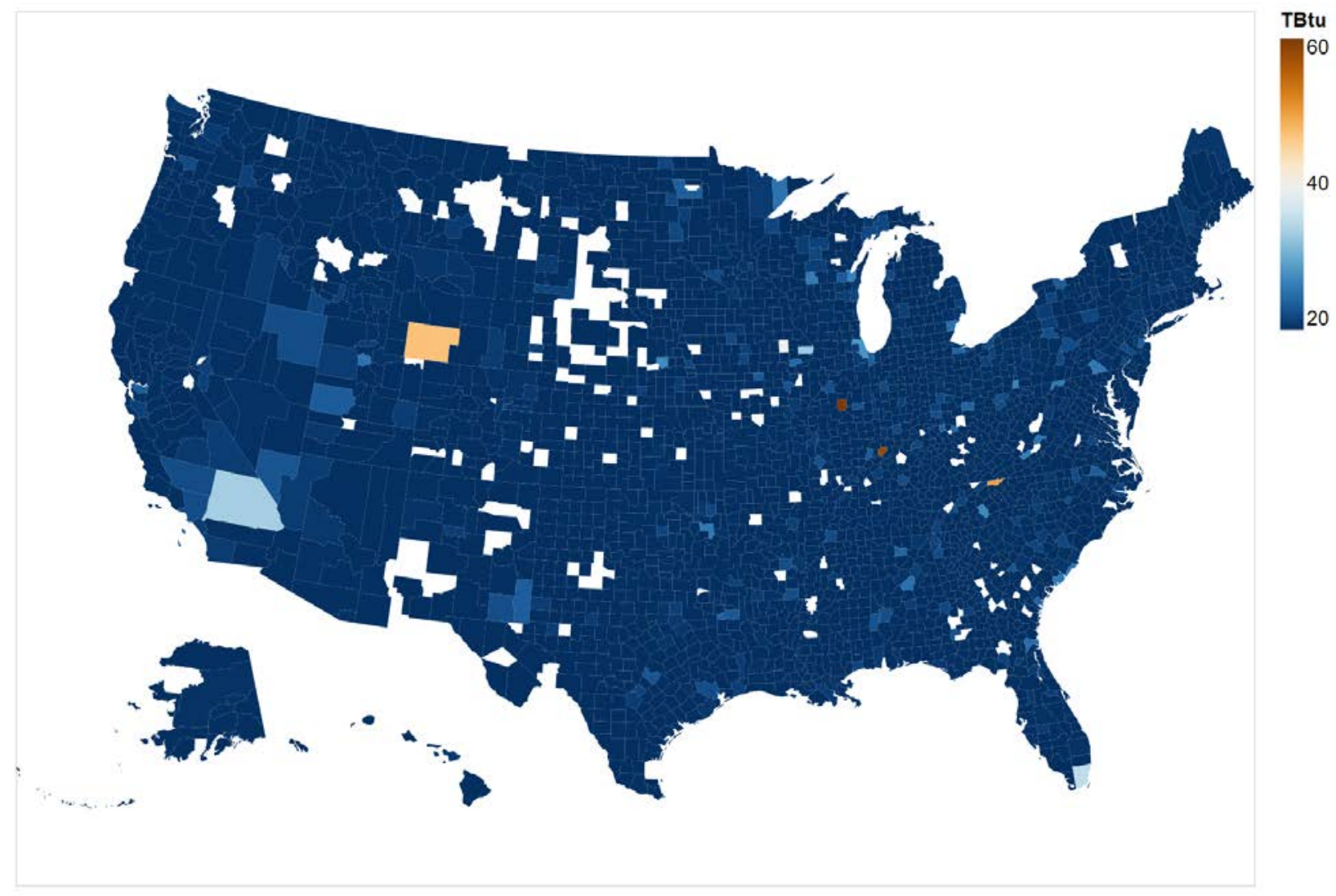

Figure 6. Estimated industrial coal use in 2014 (IET)

White shading represents an estimated value of zero.

${ }^{26}$ See https://doi.org/10.7799/1481899. 
We estimate that the largest natural gas use occurs in Harris County, Texas, as shown in Figure 7. The county, which has a large footprint of petrochemical manufacturing (NAICS 325110), refining (NAICS 324110), and crude petroleum and natural gas extraction (NAICS 211111), is responsible for about $3 \%$ of total industrial natural gas use in 2014. Other significant users of natural gas are North Slope Borough, Alaska, and Kern County, California, both of which have significant crude petroleum and natural gas extraction industries.

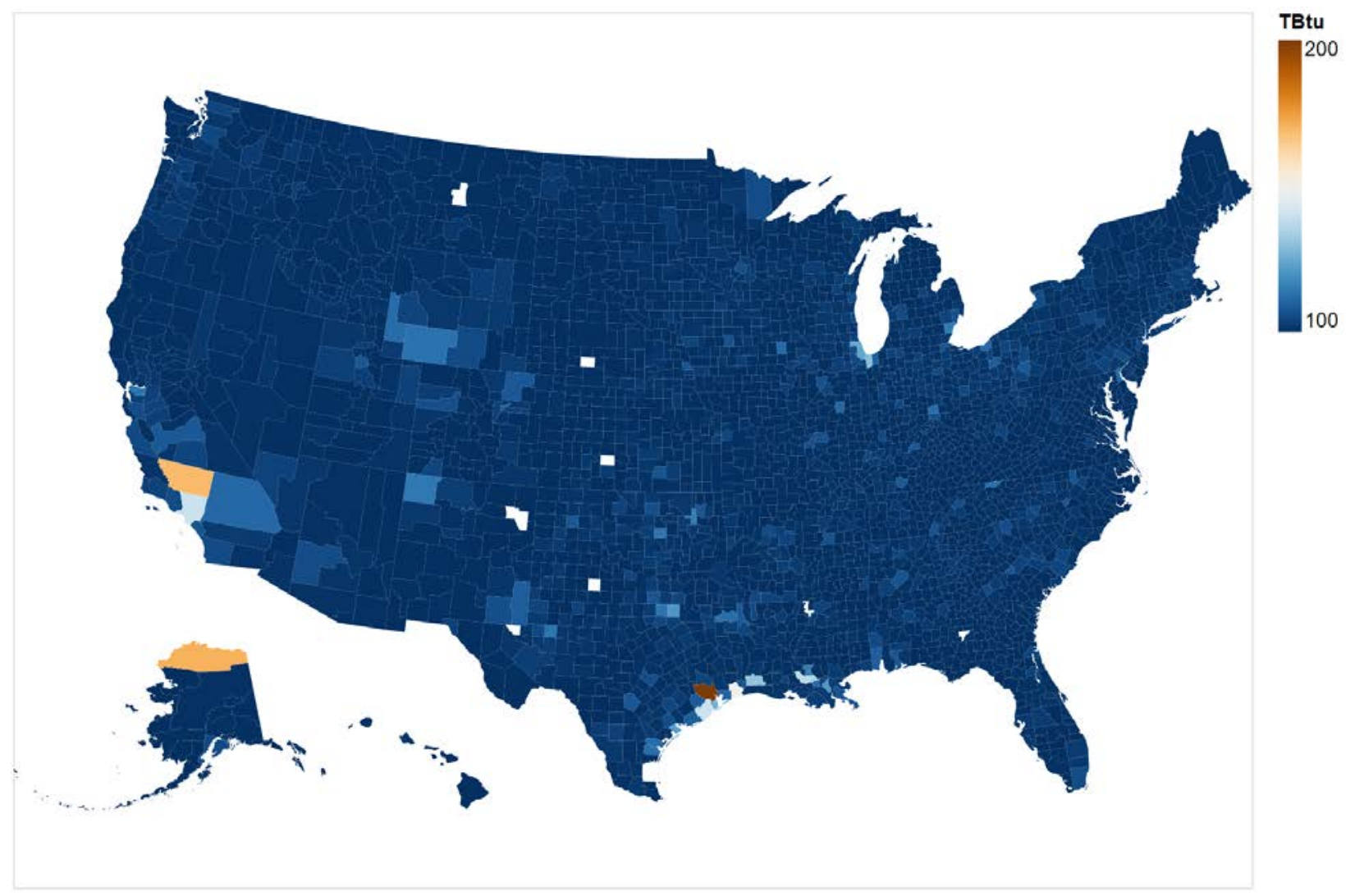

Figure 7. Estimated industrial natural gas use in 2014 (IET)

White shading represents an estimated value of zero. 
Figure 8 shows that we also calculate that Harris County, Texas, has the largest net electricity use. Other counties with significant net electricity use include Los Angeles County, California, and Cook County, Illinois. Unlike counties with significant coal and natural gas use, the large electricity-using counties are characterized more by a large overall manufacturing footprint rather than a single large industry.

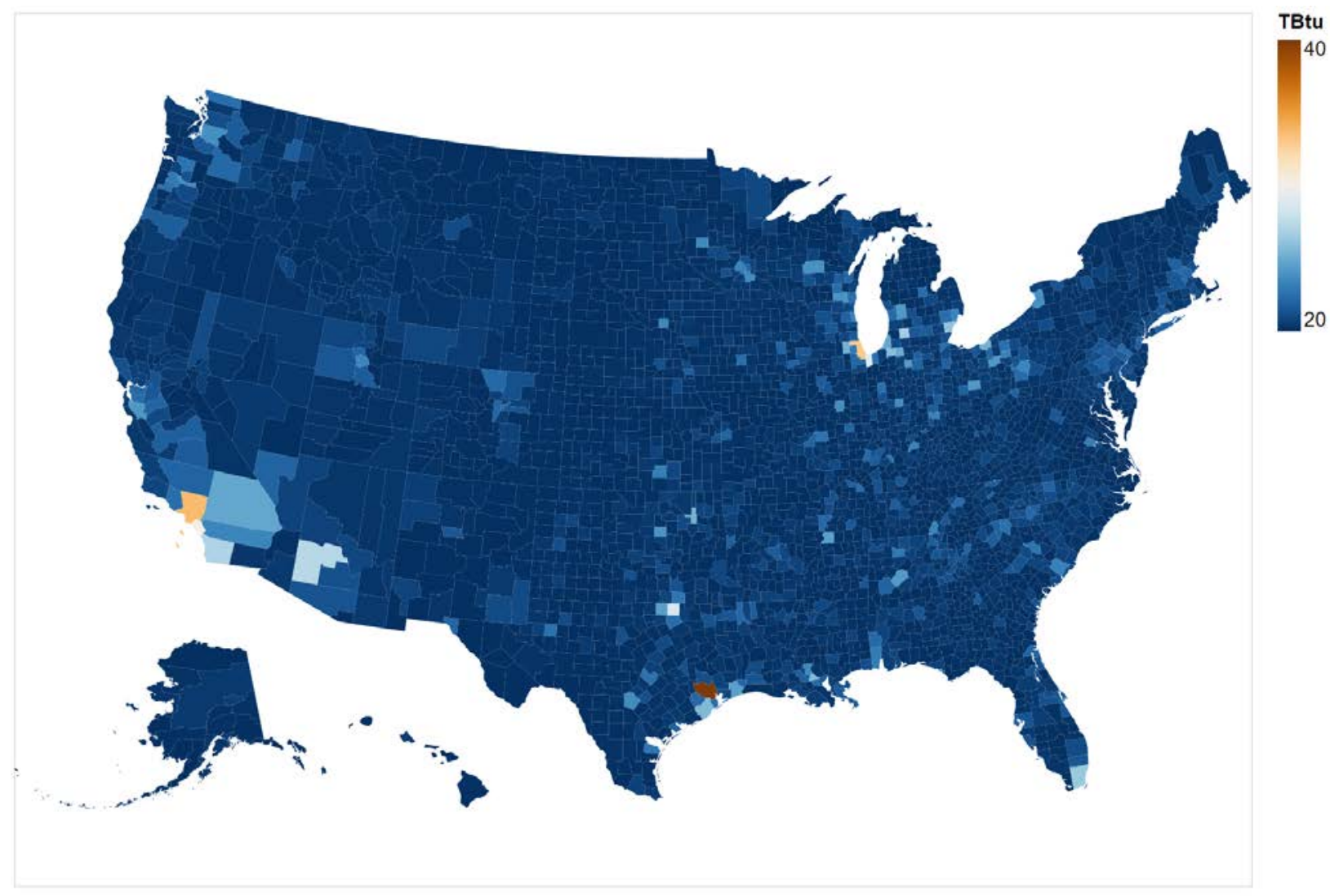

Figure 8. Estimated net electricity use in 2014 (IET) 
Figure 9 demonstrates the ability of the IET's foundational data to characterize energy use by six-digit NAICS code. Here we show total energy use for iron and steel mills and ferroalloy manufacturing (NAICS 331110). Two counties in Indiana-Lake County and Porter Countyare home to $20 \%$ of the industry total energy use. In addition to depicting energy use, the figure shows the geographic distribution of this industry

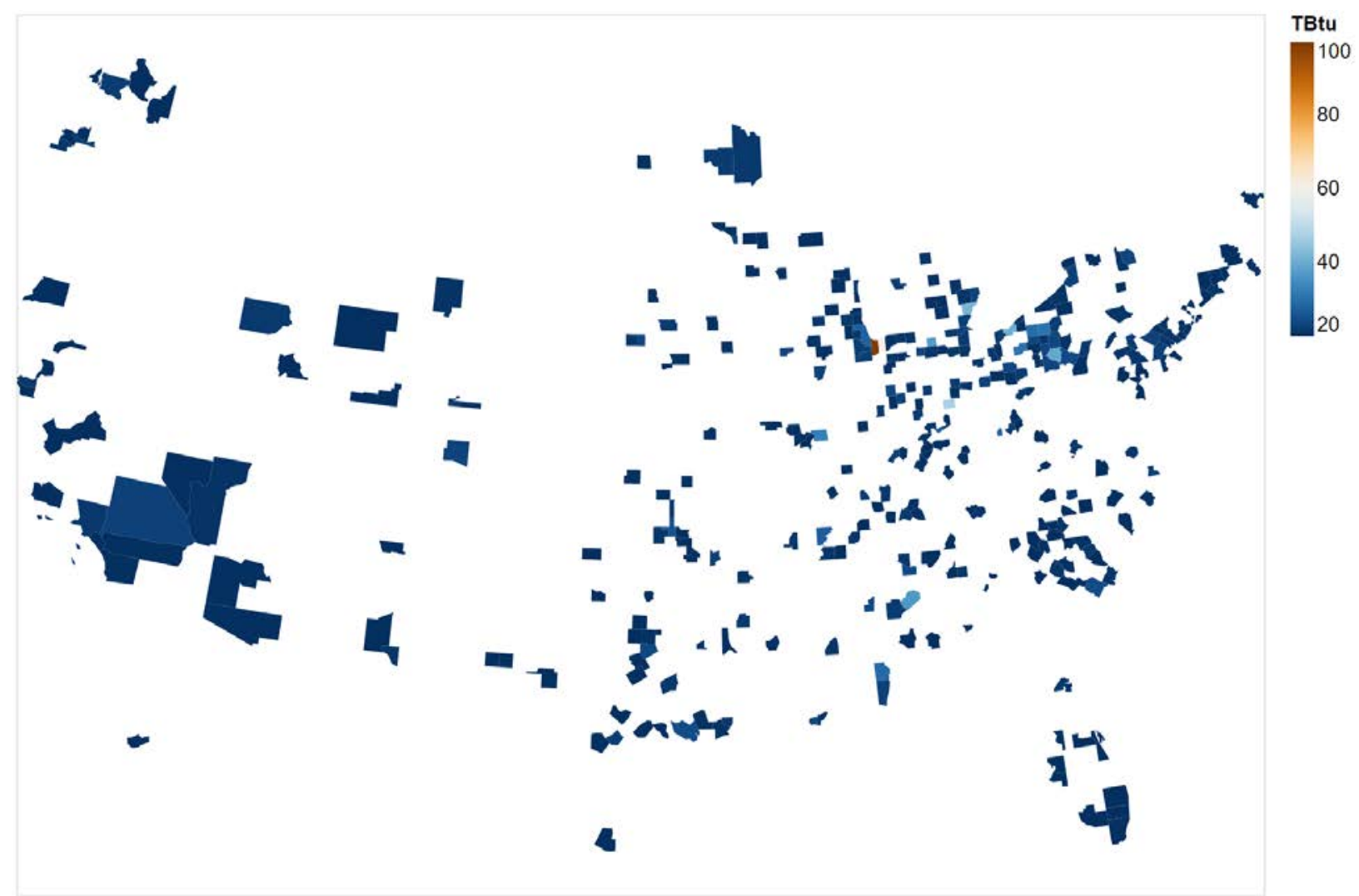

Figure 9. Estimated total energy use for iron and steel mills and ferroalloy manufacturing (NAICS 331110) in 2014 (IET) 
All previous county figures have shown absolute energy use. We have normalized total county energy use by county industry employment ${ }^{27}$ in Figure 10. North Slope Borough, Alaska stands out starkly as the largest industrial energy user on an employment-normalized basis due to its large petroleum refining and crude oil and natural gas extraction industries and relatively small industry employment.

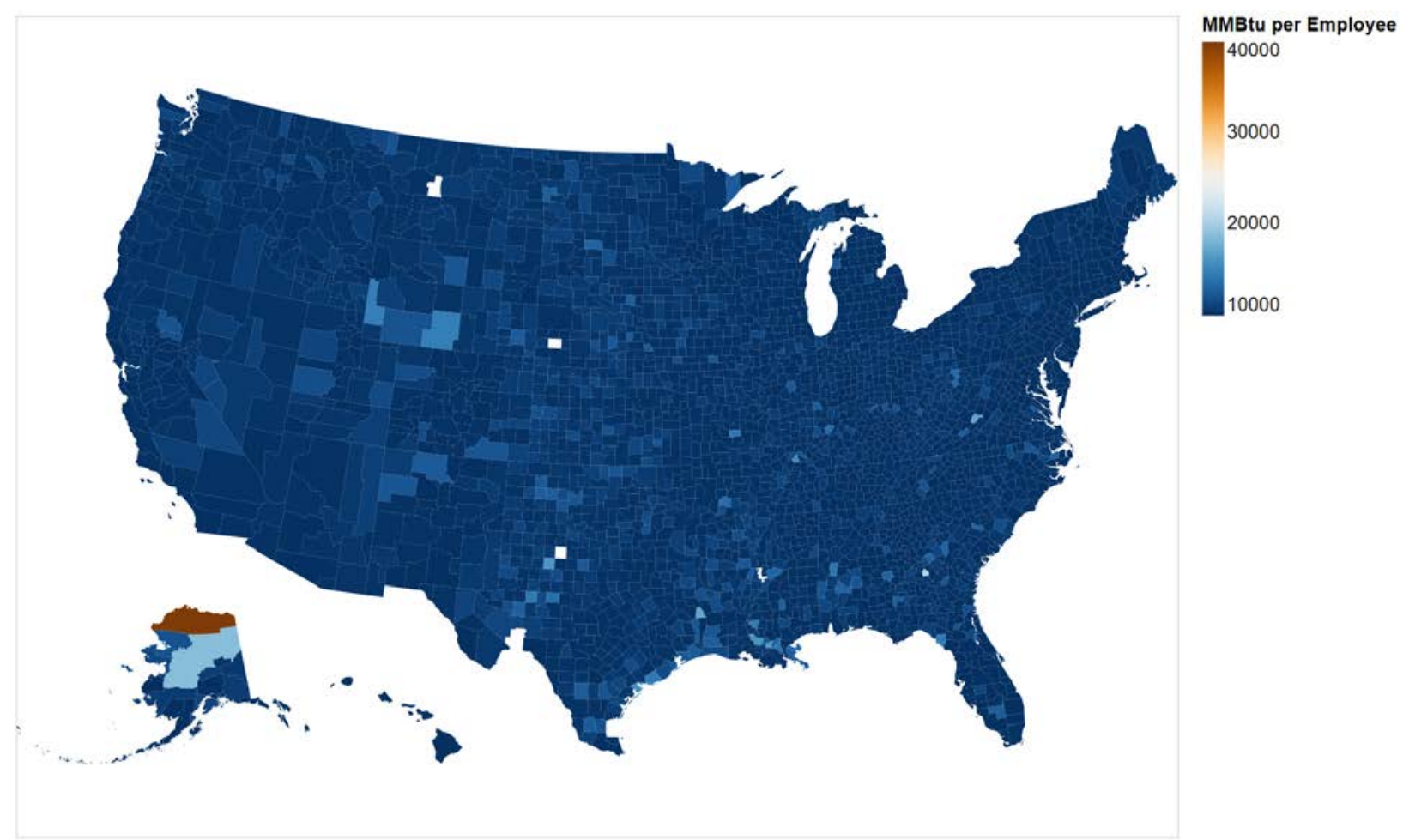

Figure 10. Estimated industrial energy use per industry employment (IET)

White shading represents an estimated value of zero.

\subsubsection{Comparisons with Published Industry Energy Data}

The IET foundational data for 2014 represent an attempt to provide new estimates of bottom-up industry energy use at an improved level of geographic and operational detail. We have not attempted to constrain our calculations to existing energy estimates from EIA or other sources, although future versions of the IET foundational data may benefit from a validation procedure with SEDS data, for example. In this section of the report, we compare the IET foundational data to existing EIA sources of industrial energy data at various levels of aggregation (e.g., national, state, census region, NAICS code, and fuel type) to establish how closely the IET matches EIA estimates.

\footnotetext{
${ }^{27}$ Employment figures are taken from CBP (U.S. Census Bureau 2016) and Agriculture Census (United States Department of Agriculture 2017) data. Note that industry employment data are not available for several counties.
} 
Table 5 compares national aggregations of the IET foundational data with analogous EIA estimates (EIA 2016, 2017f). Although the IET estimates are within $0.5 \%$ and $1 \%$ of EIA estimates for manufacturing and total industry, large differences exist for the construction sector and for residual fuel oil, liquified petroleum gas-natural gas liquids (LPG-NGL). These are areas that warrant further examination to determine why such large differences occur.

Table 5. Comparison of 2014 Industrial Energy Data Estimated by EIA and the IET Data Foundation

\begin{tabular}{|l|r|r|r|r|}
\hline $\begin{array}{l}\text { National } \\
\text { Aggregation }\end{array}$ & $\begin{array}{l}\text { EIA } \\
\text { Estimate } \\
\text { (TBtu) }\end{array}$ & $\begin{array}{l}\text { IET Data } \\
\text { Foundation } \\
\text { (TBtu) }\end{array}$ & $\begin{array}{l}\text { Difference } \\
\text { (TBtu) }\end{array}$ & $\begin{array}{l}\text { Difference } \\
\text { (\%) }\end{array}$ \\
\hline Sector & & & & \\
\hline Agriculture & 1,167 & 875 & -292 & -25 \\
\hline Construction & 714 & 1,037 & 323 & 45 \\
\hline Mining & 2,982 & 3,085 & 103 & 3 \\
\hline Manufacturing & 14,903 & 14,831 & -72 & -0.5 \\
\hline Fuel & & & & \\
\hline LPG-NGL & 432 & 200 & -232 & -54 \\
\hline Diesel & 1,361 & 1,372 & 11 & 1 \\
\hline Residual fuel oil & 35 & 147 & 112 & 324 \\
\hline Natural gas & 7,031 & 8,803 & 1,772 & 25 \\
\hline Coal & 871 & 1,109 & 238 & 27 \\
\hline Coke and breeze & 562 & 38 & -524 & -93 \\
\hline Other & 5,921 & 4,576 & $-1,345$ & -23 \\
\hline Net electricity & 3,404 & 3,582 & 178 & 5 \\
\hline Total Industry & 19,616 & 19,828 & $\mathbf{2 1 2}$ & $\mathbf{1}$ \\
\hline
\end{tabular}

a AEO 2016 (EIA 2016) is the source of EIA data unless otherwise noted. b MECS 2014 (EIA 2017f)

Table 6 summarizes the relative difference between state-level industrial energy data reported by EIA SEDS ${ }^{28}$ and the state-level aggregation of the data foundation. Note that we have also aggregated IET fuel types to match SEDS fuel designations. On average, the IET estimates for total energy use are $10 \%$ above those of SEDS. Of course, this mean value hides the variation that exists by individual state and by fuel type. Across these categories shown in Table 6, Louisiana and Hawaii appear twice as minima or maxima, which likely reflects their unique energy use; we speculate that this is the result of Louisiana's large footprint of chemical manufacturers and petroleum refineries and Hawaii's island geography.

\footnotetext{
${ }^{28}$ IET values are compared against SEDS data series names CLOCB for coal, ESICB for electricity, and NGICB for natural gas. ARICB, FNICB, FOICB, FSICB, and LUICB were subtracted from PAICB to estimate non-feedstock petroleum products use.
} 
Table 6. Difference between Industry Energy Use in 2014 Reported by EIA State Energy Data System (SEDS) (EIA 2017g) and State-Level Aggregation of Data Foundation

\begin{tabular}{|l|r|l|r|r|r|}
\hline & \multicolumn{1}{l|l|}{$\begin{array}{l}\text { Petroleum } \\
\text { Products }\end{array}$} & \multicolumn{1}{l|}{$\begin{array}{l}\text { Natural } \\
\text { Gas }\end{array}$} & \multicolumn{1}{l|}{$\begin{array}{l}\text { loal } \\
\text { Electricity }\end{array}$} & \multicolumn{1}{l|}{ Total } \\
\hline Mean & $-30 \%$ & $41 \%$ & $237 \%$ & $9 \%$ & $10 \%$ \\
\hline Median & $-45 \%$ & $8 \%$ & $35 \%$ & $7 \%$ & $9 \%$ \\
\hline Variance & $16 \%$ & $214 \%$ & $13,296 \%$ & $16 \%$ & $9 \%$ \\
\hline Minimum & $-96 \%(\mathrm{LA})$ & $-44 \%(\mathrm{LA})$ & $-88 \%(\mathrm{ND})$ & $-86 \%(\mathrm{HI})$ & $-52 \%(\mathrm{ND})$ \\
\hline Maximum & $67 \%(\mathrm{MA})$ & $955 \%(\mathrm{HI})$ & $7,756 \%(\mathrm{AK})$ & $124 \%(\mathrm{SD})$ & $137 \%(\mathrm{VT})$ \\
\hline
\end{tabular}

Negative values indicate IET values are less than SEDS values.

The largest relative differences with SEDS are for coal use. SEDS reports zero industrial coal use for Connecticut, Delaware, the District of Columbia, New Hampshire, New Jersey, Rhode Island, and Vermont. The reported value for Alaska is $0.017 \mathrm{TBtu}$ and its IET value is 1.335 TBtu; this outlier has an outsized effect on the mean and variance shown in Table 6 . The IET calculates non-zero industrial coal use for all these states and the District of Columbia based on regional-average coal intensities; only New Jersey includes facility-level data. The IET's reliance on regional-average energy intensities likely explains most of the large variation with SEDS shown in Table 6. Additionally, basing the regional-average energy intensities on 2010 MECS, instead of 2014 MECS, and CBP establishment counts unadjusted for GHGRP reporters may also explain the differences with SEDS.

However, estimates for industrial coal use in New Jersey are also based on facility-reported GHGRP emissions from coal combustion. Additional work is needed to verify whether the GHGRP is capturing energy use that the methods that inform SEDS may not. In addition to differences in estimation approaches, differences in how each data source identifies and categorizes fuel use may also contribute to the large variation with SEDS. A complete state-bystate comparison of the two data sets is included in Appendix B.

MECS provides the most detailed comparison possible with a publicly available industrial energy data source and the data foundation. To make this comparison, we aggregated the IET foundational data to the census region and by MECS NAICS code. Note that MECS does not report energy data at the six-digit NAICS level for all manufacturing industries due to confidentiality concerns. As a result, the 364 six-digit manufacturing NAICS codes provided by the data foundation are aggregated to match the 45 six-digit NAICS, 1 five-digit NAICs, 14 fourdigit NAICs, and 21 three-digit NAICS codes used by MECS.

Table 7 summarizes the relative differences between the IET foundational data and MECS 2014. We have identified the smallest and largest relative differences for each dimension of data detail - geographic and operational (industry and fuel use) — based on mean relative difference. We note that this table does not capture instances where the data foundation reports a non-zero value for energy use and MECS data are either withheld or reported as zero. A full comparison of the IET and MECS - including absolute and percent difference by all NAICS codes reported by MECs - is provided in the NREL Data Catalog. 
Table 7. Summary of Smallest and Largest Relative Differences between Data Foundation and MECS 2014 (\%)

\begin{tabular}{|l|l|l|l|l|l|l|}
\hline Dimension & \multicolumn{3}{|l|}{ Geographic } & \multicolumn{2}{l|}{ Operational: Industry } & \multicolumn{2}{l|}{ Operational: Fuel Use } \\
\hline & South & Midwest & $\begin{array}{l}\text { Paper (Except } \\
\text { Newsprint } \\
\text { Mills) }\end{array}$ & $\begin{array}{l}\text { Other Aluminum } \\
\text { Rolling, Drawing } \\
\text { and Extruding }\end{array}$ & Diesel & Coal \\
\hline Mean & 21 & 45 & 0.5 & 1,680 & 4 & 126 \\
\hline Variance & 68 & 107 & 8 & 5 & 89 & 179 \\
\hline Range & {$[-91,582]$} & {$[-44,663]$} & {$[-10,13]$} & {$[1,680,1,695]$} & {$[-95,570]$} & {$[-100$,} \\
$2,800]$
\end{tabular}

a MECS reports Other Aluminum Rolling, Drawing, and Extruding for only the South Census Region and the entire United States. 


\section{IET Components}

The IET is currently composed of four components in addition to its data foundation: stock turnover, energy efficiency, fuel switching, and emissions. The stock turnover component uses projections of industry value of shipments by census region as a proxy to capture capital equipment stock retirements and new investment. The energy efficiency component implements changes to the UEC by end use, industry, and census region to account for improvements to energy efficiency. Fuel switching is conducted by substituting an alternate energy source (currently limited to electricity) in new capital stock investment. The IET's emissions component (currently limited to GHG emissions) calculates emissions associated with projected energy use after accounting for any changes to fuel switching or energy efficiency.

The IET does not include construction industries in its stock turnover, energy efficiency, fuel switching, and emissions calculations because of the lack of data on energy end-use disaggregation. However, county-level construction industry energy use can be found in the IET's foundational data.

\subsection{Stock Turnover}

The stock turnover component enables the IET to account for the retrofit of existing and purchase of new industrial capital stock. This feature is used to project future energy use and to capture the effects of installing energy-efficient equipment and fuel switching. As discussed in detail below, the IET does not use physical stock data, but instead uses changes in industrial value of shipments as proxies.

IET uses a top-down modeling approach similar to portions of the Industrial Demand Module (IDM) of the National Energy Modeling System (NEMS) (EIA 2014e). Future energy use is projected by census region and industry using the AEO 2017 Reference Case industry value of shipments (EIA 2017a). The IET projects energy use and emissions on five-year increments due to the computational requirements of its county-level calculations. ${ }^{29}$ Industry stock is partitioned in two categories: pre-2014 (or, existing) and post-2014 (or, new) stock. For simplicity, the initial version of the IET assumes both pre-2014 and post-2014 stock across all industries and end uses are replaced linearly at default lifetimes of 20 years and 30 years respectively. All existing stock is assumed to begin retiring at 5\% per year starting in 2015. The IET assumes new stock is added to replace retired existing stock and to add capacity when value of shipments increases from the previous year. Future IET versions could include more sophisticated retirement behavior (e.g., using probability distributions or logistic functions, retirement behavior as a function of industry sector, or a capital vintage model).

\footnotetext{
${ }^{29}$ We note that there are additional opportunities to improve the performance of the IET (e.g., code optimization or refactoring, including the use of relational databases), but these were not implemented in this version of the tool.
} 


\subsection{Energy Efficiency}

Energy efficiency is represented by a change in the UECs of pre- and post-2014 stock calculated by the IET's stock turnover component. We implement changes to UECs with an assumed constant annual change in the form of technology possibility curves (TPCs), an approach used by the Industrial Demand Module of NEMS to capture the relative differences in energy use between existing technologies and future, more-efficient technologies, as well as incremental improvement to the efficiency of existing technologies (EIA 2018d). TPCs are defined for existing and new equipment by industry and end use by fuel type for electricity, steam, and natural gas. We assumed an average TPC for missing fuel types. Examples of TPCs are shown in Table 8 along with energy efficiency potentials estimated by DOE bandwidth studies, which are described in the following paragraph.

Energy efficiency beyond the baseline assumptions is implemented as efficiency bounds defined by DOE bandwidth studies (DOE n.d.). Energy consumption bounds (bandwidths) in these studies are defined consistently as:

- State-of-the-art: the minimum energy required assuming adoption of best technologies and practices available worldwide

- Practical minimum: the minimum energy required assuming deployment of the applied R\&D technologies under development worldwide

- Thermodynamic minimum: the minimum energy theoretically required under ideal conditions.

Energy efficiency improvement is currently implemented in the IET as a constant annual decrease in UEC from 2015 to 2050. The default efficiency assumptions are based on TPCs defined for AEO 2014 (EIA 2014a). IET users can choose to implement energy efficiency beyond these default assumptions by scaling bandwidth efficiency assumptions for state-of-theart and practical minimum levels by industry. For instance, a user may implement one energy efficiency scenario that assumes $50 \%$ of state-of-the-art level by 2050 and another scenario that assumes $100 \%$ of practical minimum level for chemicals and primary metals industries. Table 8 summarizes the bandwidth studies used by the IET (DOE 2007, 2015a, 2015b, 2015c, 2015d, 2017a, 2017b, 2017c, 2017d, 2017e, 2017f, 2017g) and the corresponding TPC equivalent range; a detailed listing of industries and efficiency bounds is provided in Appendix C. Note that unlike TPCs, which in many instances are defined by industry, end use, and fuel type, the bandwidth efficiencies are specified only by sector. 
Table 8. Summary of Energy Efficiency Potentials from Industry Bandwidth Studies and TPCs

\begin{tabular}{|l|c|c|c|}
\hline Sector & $\begin{array}{l}\text { Reduction from } \\
\text { Current Typical to } \\
\text { State-of-the-Art (\%) }\end{array}$ & $\begin{array}{l}\text { Reduction from } \\
\text { Current Typical to } \\
\text { Practical Minimum (\%) }\end{array}$ & $\begin{array}{l}\text { TPC (New } \\
\text { Equipment) (\%) }\end{array}$ \\
\hline Food & $8-64$ & $20-75$ & $6-33$ \\
\hline Beverage and Tobacco & $10-18$ & $20-23$ & $6-33$ \\
\hline Paper & $44-46$ & $61-74$ & $5-68$ \\
\hline Chemicals & $6-40$ & $37-64$ & $14-61$ \\
\hline Plastics and Rubber & $15-37$ & $25-47$ & $19-61$ \\
\hline Petroleum and Coal Products & 13 & 40 & not defined $^{\text {b }}$ \\
\hline Primary Metals & $3-67$ & $25-79$ & $0-66$ \\
\hline Nonmetallic Minerals & $18-49$ & $32-53$ & $4-21$ \\
\hline Mining (except oil and gas) & $20-34$ & $55-70$ & not defined $^{\text {b }}$ \\
\hline
\end{tabular}

a TPC values represent the energy use of new equipment stock relative to 2010 . Values have been linearly extrapolated to 2050 from 2040 values.

b TPCs are not defined for this sector.

\subsection{Fuel Switching}

The IET adopts a simplified approach to representing user-defined substitution of existing fuel use with an alternate fuel. The current version of the IET limits fuel switching to electrification, but the capability to substitute other fuels could be added to the tool. Fuel switching is integrated with stock turnover calculations; users may specify the industry, end use, temperature band, and portion of fuel use switched by 2050 . The IET assumes a constant annual fraction of new stock fuel use is substituted with the alternate fuel type. Other representations of fuel switching behavior (e.g., logistic or S-curve adoption) are not included in this version of the IET, but they have been identified as potential future tool expansions.

Unlike other models that provide fuel switching functionality (e.g., EnergyPATHWAYS ${ }^{30}$ ) the IET does not account for the relative efficiency of incumbent and substitute technologies at this time. Energy use does not change in fuel switching scenarios as a result. The IET does not limit the types of end uses that can be selected for fuel switching scenarios.

\subsection{Emissions}

GHG emissions associated with base-year and projected energy use are calculated by fuel type (i.e., coal, coke and breeze, natural gas, diesel, LPG NGL, residual fuel oil, and "other" fuel types) using EPA emissions factors for carbon dioxide $\left(\mathrm{CO}_{2}\right)$, methane $\left(\mathrm{CH}_{4}\right)$, and nitrous oxide $\left(\mathrm{N}_{2} \mathrm{O}\right)$ (EPA 2018). For "other" fuel, which includes fuels ranging from agricultural residues to used vehicle tires, we assigned the third quartile of the emission factors of all the other fuel types. Emission factors for each fuel were converted into $\mathrm{CO}_{2}$ equivalent.

\footnotetext{
30 See "EnergyPATHWAYS", GitHub, https://github.com/energyPATHWAYS/EnergyPATHWAYS
} 
GHG emissions associated with electricity purchases reflect regional generation fuel mixes by year and are calculated using either EPA data for 2014 or AEO 2017 data for 2015-2050. Baseyear (2014) emissions are calculated using EPA's Emissions and Generation Resource Integrated Database (eGRID) Power Profiler Emissions Tool (EPA 2014). The tool identifies electricity generation emission factors by ZIP code and eGRID region; ZIP codes associated with more than one eGRID region are assigned an emission factor equal to the average of the regions. These ZIP code emission factors are then mapped to the IET's county FIPS codes. Regional electricity emission factors are projected for 2015 to 2050 using annual generation fuel mix data from AEO 2017, which are mapped to eGRID region and county FIPS codes.

We have introduced functionality that enables users to specify a percentage-point increase in renewable electricity penetration that is achieved by 2050 . The IET proportionally reduces electricity generation emissions factor for each year. ${ }^{31}$

\footnotetext{
${ }^{31}$ In the future, this functionality could be complemented by integrating renewable energy penetration assumptions from AEO side cases and NREL's Standard Scenarios. For information about the latter, see "Annual Technology Baseline and Standard Scenarios," NREL, https://www.nrel.gov/analysis/data-tech-baseline.html.
} 


\section{Case Studies}

We present two case studies as illustrative examples of applications of the IET and two baseline scenarios. These four sets of results can be considered bounding cases for the IET. The baseline scenarios - one that assumes no stock turnover and the other that assumes stock turnover with baseline efficiency - represent projections that assume constant 2014 efficiency or that mimic AEO Reference Case TPCs respectively. The two case studies - one for fuel switching and one for energy efficiency - achieve the maximum values for fuel switching and energy efficiency by 2050 and represent the technical potential for each of these considerations. We note that although using the maximum values for fuel switching and efficiency are not intended to be realistic assumptions and projections of possible future scenarios, the case studies are useful for presenting bounds for the current version of the IET.

Figure 11 (page 32) shows projections for total industry GHG emissions of the four IET scenarios, the AEO 2017 Reference Case, and EIA historical emissions from 1990 to 2017 (EIA 2018e). Without incorporating stock turnover behavior, emissions follow a trajectory set by the industry value of shipments projections and electricity grid mix assumptions of AEO 2017. With stock turnover behavior (with baseline energy efficiency assumptions from AEO TPCs) included, emissions in 2050 decrease to $50 \%$ of the baseline scenario without stock turnover and to about $40 \%$ of the AEO 2017 Reference Case. The fuel switching and energy efficiency scenarios build on the baseline stock scenario by assuming the same stock turnover behavior and achieving maximum fuel switching or energy efficiency potential by 2050 .

The emissions and energy results point to large differences in assumptions and application of energy efficiency and stock turnover in the IET and NEMS. For example, by the release of AEO 2017, NEMS had implemented process flow models - which do not use TPCs to represent energy efficiency - for the paper, glass, cement and lime, iron and steel, and aluminum industries. UEC in NEMS may also be defined in terms of physical output (i.e., tons) in addition to monetary output (i.e., value of shipments).

Regarding stock turnover modeling, NEMS includes a third equipment vintage and it assumes logistic retirement. Stock turnover occurs much more slowly in NEMS than in the IET, which may reflect assumptions regarding a larger prevalence of equipment retrofitting. Faster retirement assumptions - particularly of existing stock - introduces much more efficient stock more quickly, compounding the projected reduction in energy use. The IET defaults for existing and new stock lifetimes are equivalent to annual retirement rates of $5 \%$ and $3.3 \%$ respectively. These are nearly four times as large as NEMS annual retirement rate assumptions of $1.3 \%-1.7 \%$ per year (EIA 2017h). ${ }^{32}$ However, researchers have found that expected equipment lifetimes are not significant inputs into capital investment decisions without policy or market incentives (Lempert et al. 2002).

\footnotetext{
32 These NEMS retirement rate assumptions are for the industries represented by end use models (i.e., food products, bulk chemicals, metal-based durables, wood products, plastics and rubber products, and balance of manufacturing). Industries represented by process flow models (i.e., paper, glass, cement and lime, iron and steel, and aluminum) assume a stock lifetime of 20 or 30 years.
} 


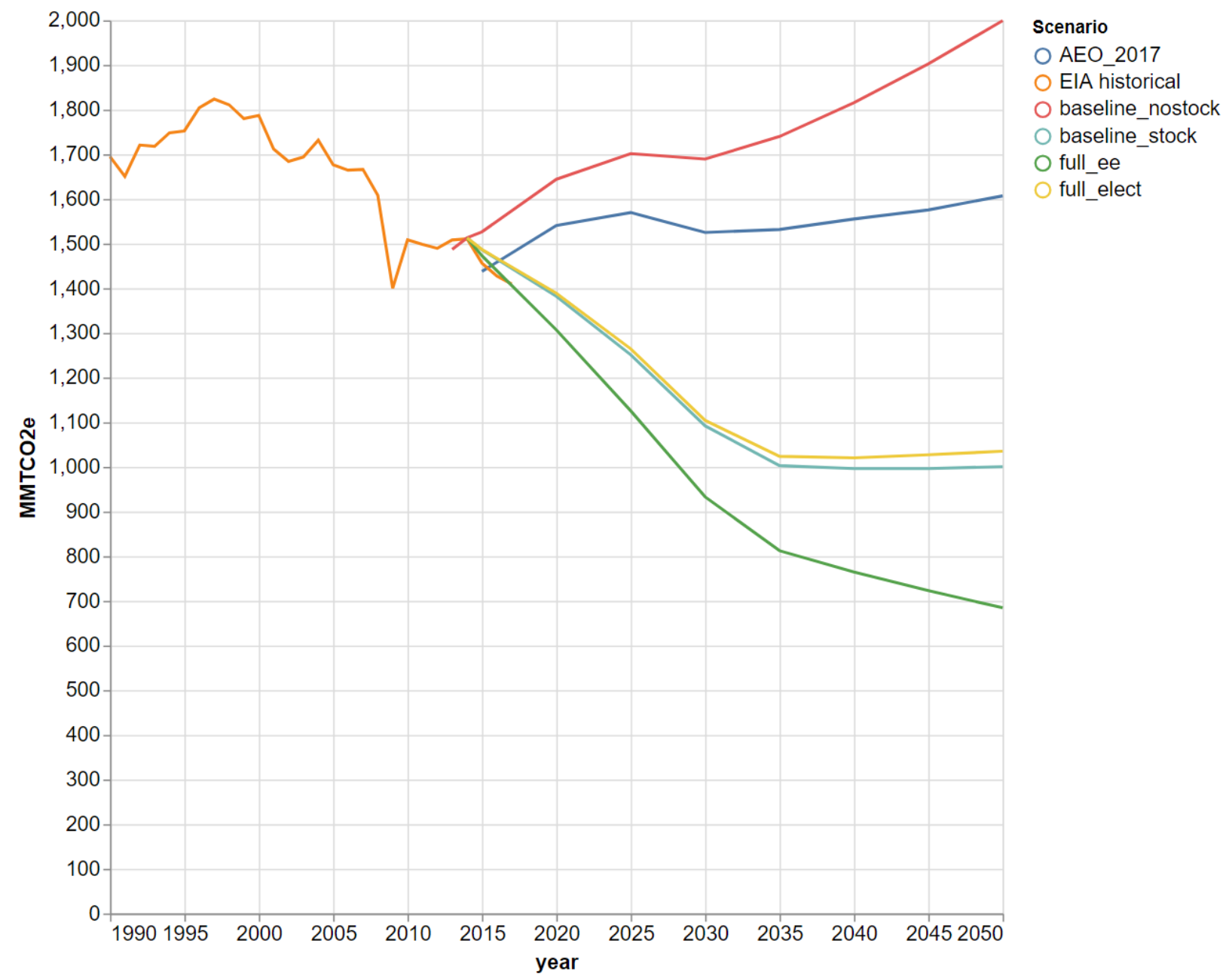

Figure 11. National industry historical ${ }^{a}$ total greenhouse gas emissions and projections by scenario

a Historical emissions include feedstock emissions.

baseline_nostock = baseline assumptions with no stock turnover, baseline assumptions with stock turnover, full_ee = energy efficiency case study, and full_elect = fuel switching case study

Figure 12 compares industry energy projections by fuel type for the AEO 2017 Reference Case and the IET baseline stock turnover scenario. As with GHG emissions, the IET projects decreasing energy use until 2035, after which energy use gradually increases through 2050. The fuel type composition of each set of projections also exhibits differences. For instance, the IET begins with a larger share of coal use that increases over time. Conversely, the relative use of coal in AEO 2017 decreases over time. 

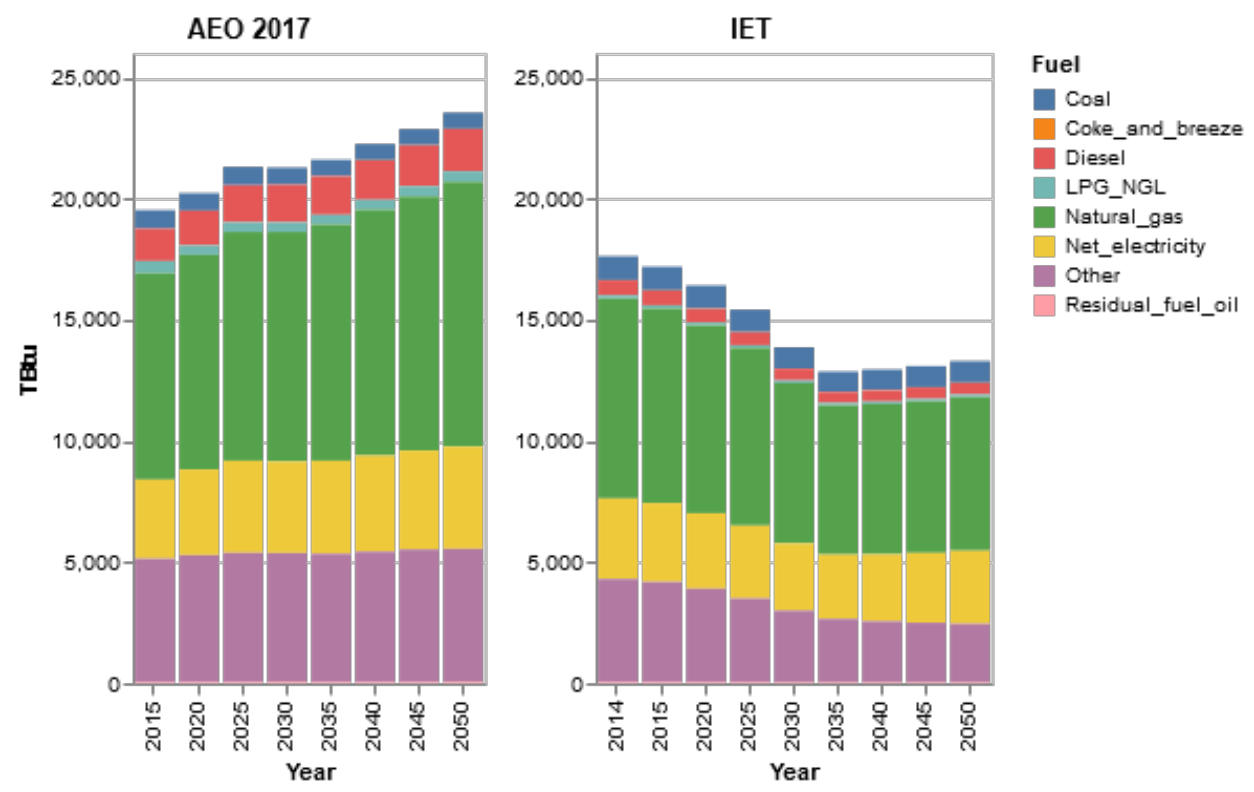

Cosl

Coke_and_breeze

Diesel

LPG_NGL

Natural_gas

Net_electricity

Other

Residusl_fuel_oil

(a)
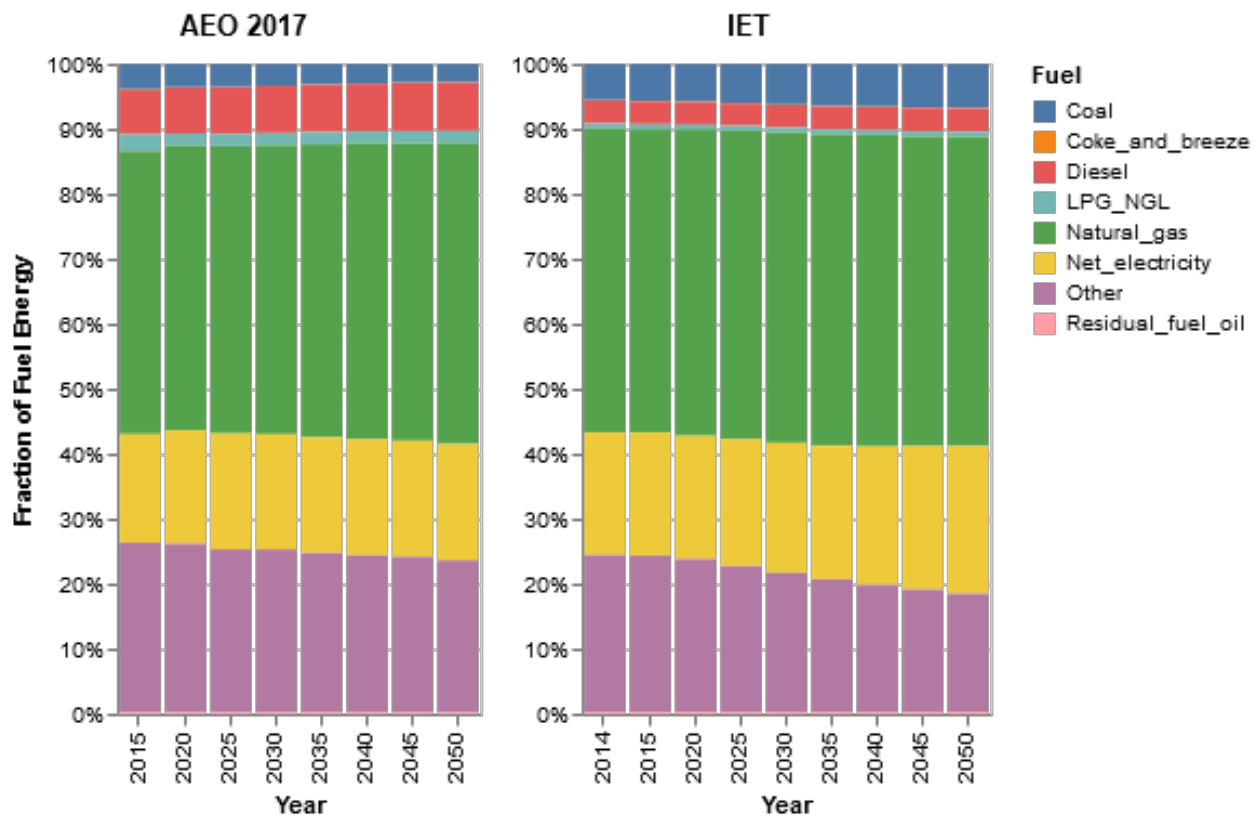

(b)

Figure 12. Comparison of (a) absolute and (b) relative national industry fuel energy projections from AEO 2017 and IET Baseline Stock scenario

The national results by scenario shown in Figure 11 belie large variation that exists from county to county. The following sections discuss the fuel switching and energy efficiency case studies in detail and demonstrate the IET's analysis resolution by presenting results at the county level. 


\subsection{Fuel Switching}

We assume for our fuel switching case study that $100 \%$ of new stock additions for all end uses in all industries are electrified by 2050 following a linear annual increase beginning in 2015 . This leads to near-zero use of coal and natural gas, and a proportional increase in net electricity use by 2050 , as shown in Figure 13. Note again that the IET's fuel switching calculations do not currently account for relative differences in energy efficiency between existing technologies and substitute technologies.
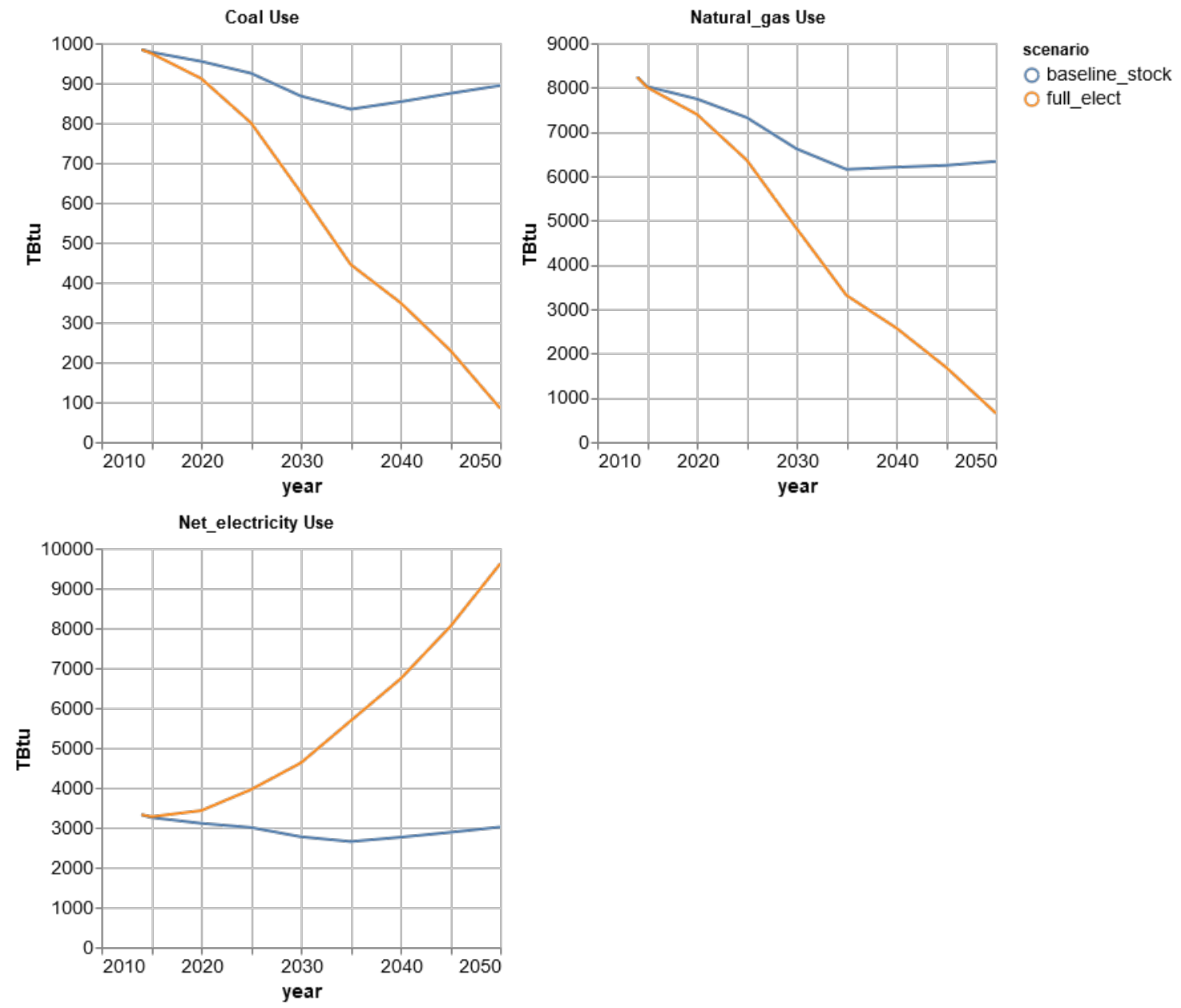

Figure 13. IET national projected coal, natural gas, and electricity use in baseline and fuel switching scenarios

The GHG impacts of the fuel switching scenario are a function of the difference in emissions intensity of the incumbent combustion fuel and grid electricity. As shown by Figure 14, when eGRID emission factors are extrapolated based on annual AEO 2017 grid mix projections to 2050, census region electricity emission factors are greater than direct natural gas combustion. The electricity emission factor for the Midwest and South Census Regions is greater than direct coal combustion. We also note that the IET does not consider supply-side behavior related to changes in electricity demand or the implications for electricity generation emissions rates. Meeting the $300 \%$ increase in electricity demand by 2050 would likely require new generation to be built, which would affect emissions rates. 


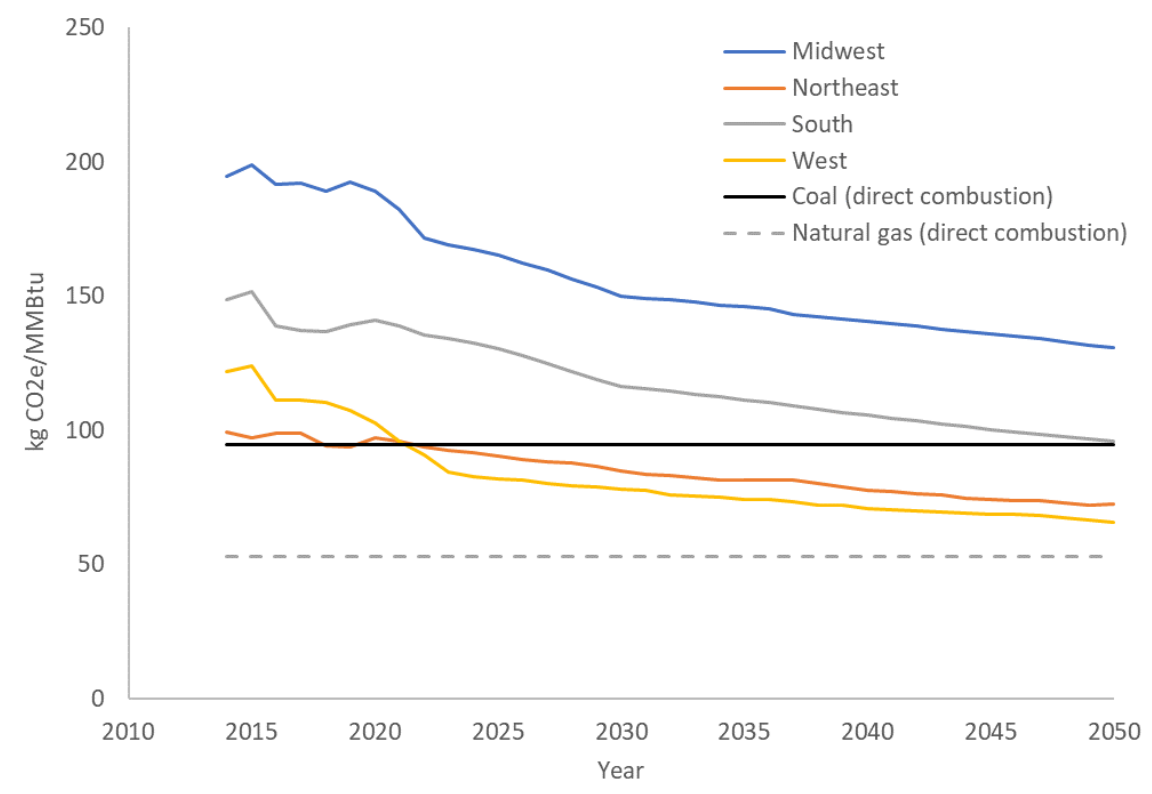

Figure 14. IET electricity generation emission factor by census region based on AEO 2017 projections

$$
\mathrm{kg}=\text { kilograms }
$$

Without assuming additional renewable electricity penetration beyond AEO 2017 assumptions, ${ }^{33}$ the fuel switching scenario projects that due to the electricity grid mix and prevalence of direct combustion of natural gas most counties would increase emissions by 2050 (i.e., have negative emissions savings) as shown in Figure 15. The largest exception is San Patricio County, Texas, where emissions are projected to decrease in 2050 relative to baseline by nearly $350 \%$. This indicates that industrial facilities in the county are selling or otherwise transferring more electricity for use by other facilities than they are using on site. ${ }^{34}$

Although it is not shown in Figure 15, the fuel switching scenario changes the location of emissions from facilities to power generating station. This change is not important for the impacts of GHG emissions, but it would affect the distribution of impacts from criteria air pollutants, for example.

\footnotetext{
${ }^{33}$ The range of renewables and nuclear portion of electricity generation by NEMS Electricity Market Module Region in 2050 is from 22\% (Northeast Power Coordinating Council) to 75\% (Western Electric Coordinating Council)

${ }^{34}$ This large negative net electricity value may demonstrate the limitation of using EIA Form-923 data for facilitylevel electricity use.
} 


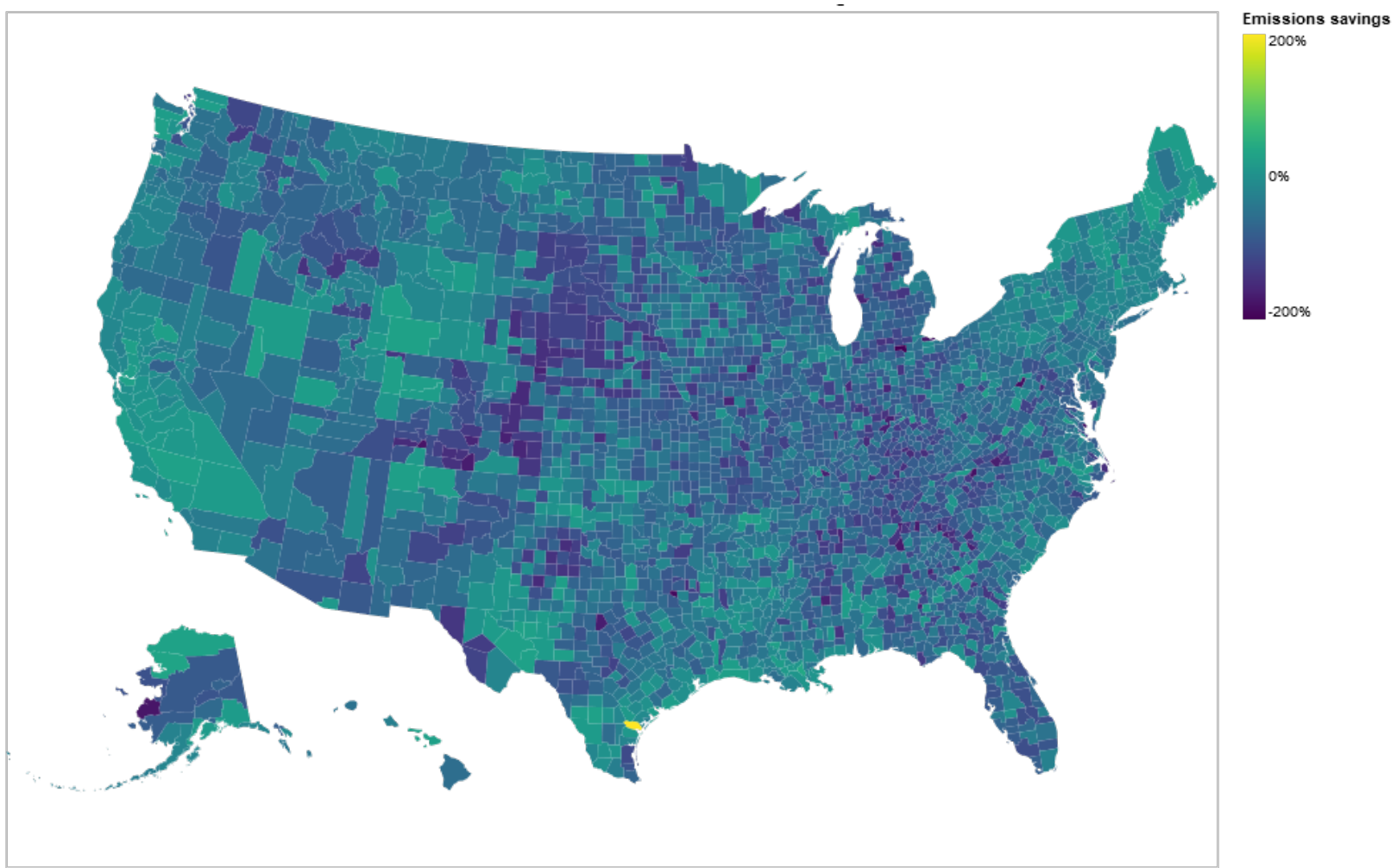

Figure 15. IET fuel switching scenario: Relative emissions savings by county in $\mathbf{2 0 5 0}$

\subsection{Energy Efficiency}

The energy efficiency case study assumes all practical minimum energy efficiency improvements are achieved by 2050 . This means food industries reduce their UEC (energy per value of shipments) by $20 \%-75 \%$ of 2014 UEC values by 2050 . Figure 16 shows the GHG emissions implications of these efficiency levels by energy end use. Under the baseline efficiency assumptions, all end uses experience strong GHG reductions until 2035; at that point, emissions from process heating and other end uses begin to increase through 2050 . This is likely the result of a smaller annual improvement in baseline energy efficiency that occurs after all existing stock has been replaced by more energy-efficient new stock. At the same time, the annual value of shipments growth from 2035 to 2050 is similar to projections for 2014-2035 for many industries.

The practical minimum efficiency levels have the largest impact on emissions from CHP and/or cogeneration, conventional boilers, and process heating. We note that the changes to end-use emissions are not a function of bandwidth efficiencies defined at the end-use level; instead, bandwidth efficiency is defined only at the industry level. Consequently, industries that have large GHG emissions from CHP and/or cogeneration also have large practical minimum energy reduction. 

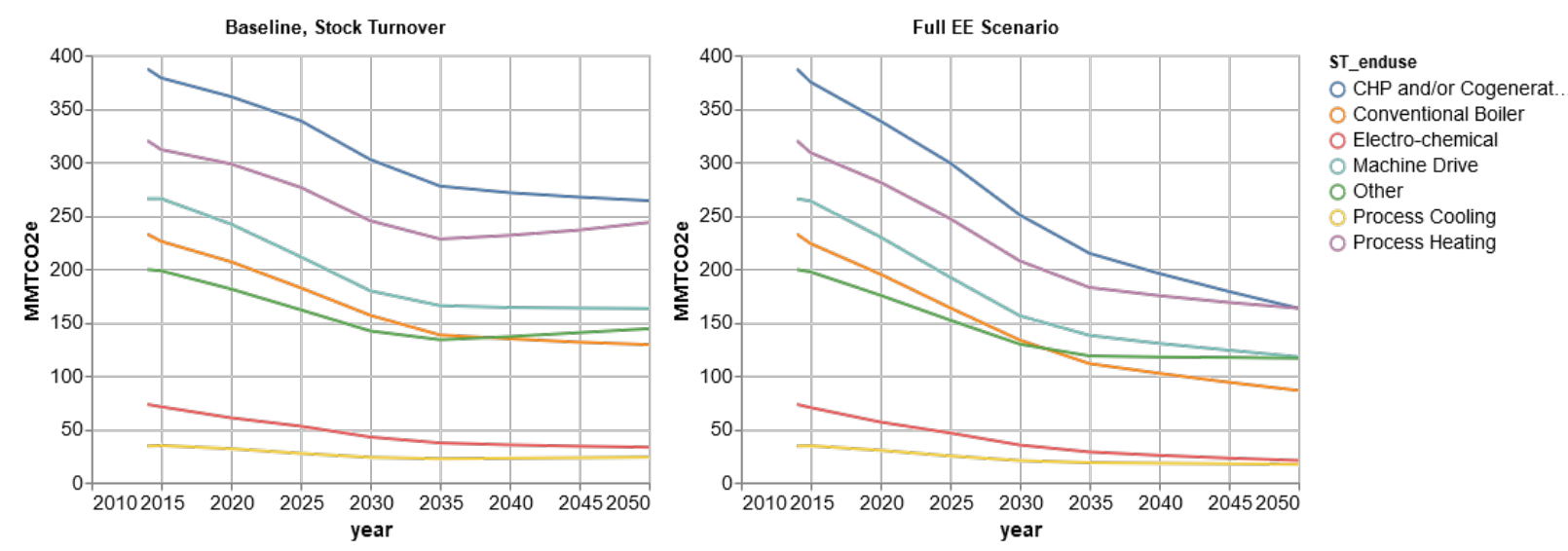

Figure 16. IET baseline and energy efficiency scenario projected emissions by end use $\mathrm{CHP}=$ combined heat and power, $\mathrm{EE}=$ energy efficiency, $\mathrm{MMTCO} e=$ million metric tons of carbon dioxide equivalent, and ST_enduse = energy end use category

Figure 17 depicts the projected emissions savings by county of achieving practical minimum efficiency levels by 2050. These results reflect the industrial composition of each county and are analogous to technical potential (i.e., no consideration given to costs) estimates. We note that counties showing very low emissions savings are likely to have a higher portion of industries, such as agriculture and some mining subsectors, not covered by DOE bandwidth studies. A closer inspection of these counties could help identify gaps in current efforts to improve energy efficiency, although the counties may be less important in terms of their absolute energy use and GHG emissions. 


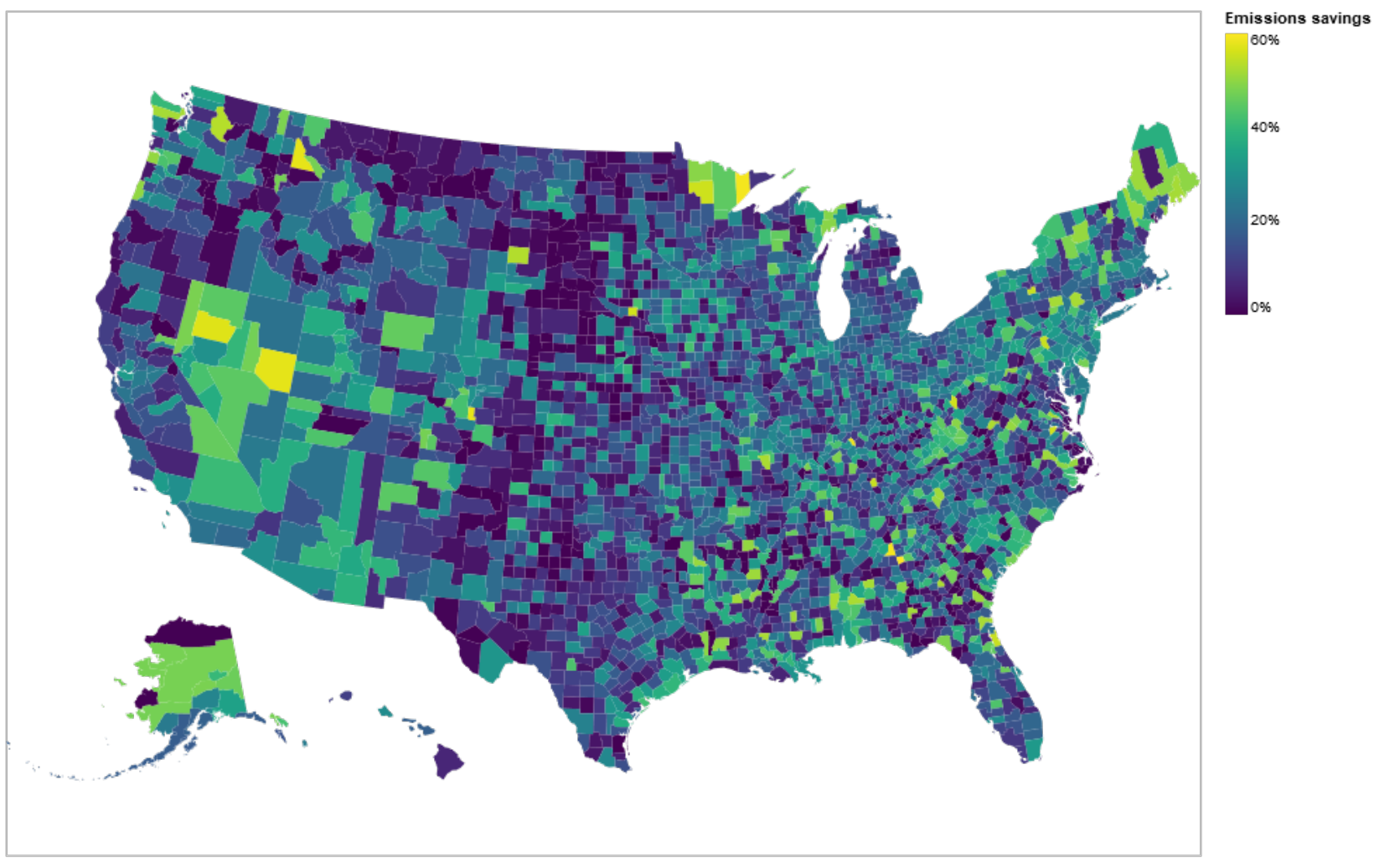

Figure 17. IET energy efficiency scenario emissions savings in $\mathbf{2 0 5 0}$ relative to baseline scenario 


\section{Data Improvements and Tool Expansion}

The IET is an open-source, transparent, and flexible tool for exploring energy and emissions scenarios for the industrial sector. To make the IET and its data more useful, we have identified several important areas for improved data and expanded functionality. Addressing these areas would provide additional confidence in the IET's foundational data, an improved user experience, and the ability to analyze a larger set of factors that affect industrial energy use and associated emissions.

\section{IET Foundational Data}

- Investigate further the large differences with SEDS, 2014 MECS, and other publicly available data sets. Additional analysis is needed to determine where the estimation approaches may be inaccurate and where they capture energy use missed by EIA fuel use and consumption surveys.

- Improve coverage for end uses in construction and agriculture to enable the IET to capture these industries by expanding the search for data sources and contact additional subject matter experts.

- Update foundational data to use 2014 MECS data in its regional average calculation approach for manufacturing. This update may result in a closer approximation to publicly available energy data.

2. IET Components

- Create a graphical user interface to simplify the user experience and make the IET more approachable and usable for a wider audience.

- Automate results visualization to provide several standard visual outputs, including energy and emissions projections on the county, census region, end-use, and industry levels. Current visualizations must be created manually, which can be time consuming.

- Expand fuel switching capabilities by including additional fuel types (e.g., biomass). Fuel switching is currently limited to electrification and adding fuel types would enable users greater flexibility for assessing strategies that affect industrial energy use and emissions.

- More closely examine the drivers behind differences with AEO 2017 emissions and energy projections. We believe that these are related to assumptions for stock lifetime and energy efficiency projection. Establishing how exactly these assumptions lead to different results would provide a better understanding of how the IET relates to existing industry energy models.

○ Integrate the hybrid dynamic IO model within the IET framework, providing users with the ability to explore potential energy and emissions implications of material efficiency strategies.

- Develop CHP functionality to better represent that end use and to address the boundary issues created by quantifying net electricity and not total electricity use. 


\section{Conclusions}

Studies of industrial energy use typically mention the sector's heterogeneity and complexity as modeling barriers. One of the more significant impediments to analyzing and building models of U.S. industrial energy use is the lack of current disaggregated data. The IET addresses some of these barriers by building an open-source, transparent, and flexible tool that operates on geographically and operationally disaggregated data. The IET's energy and emissions scenarios are based on a simplified approach that allows users to modify pre-populated inputs for achieving energy efficiency, rate of equipment stock turnover, and future penetration of renewable electricity.

The IET is built on an industry energy data foundation that estimates detailed county-level industrial energy use in 2014 at the four- to six-digit NAICS code level. This data set is based on facility-level calculations of energy use for the largest energy-using industries. We have further improved the operational characterization of industrial energy use by identifying temperature requirements for boiler and process heating energy use by industry.

We also demonstrated the functionality of the IET by providing results of baseline assumptions and two illustrative case studies that explore the IET's upper bounds of energy efficiency and fuel switching assumptions. By comparing these results with NEMS and AEO 2017, we find that the IET's current baseline assumptions result in larger reductions in energy use and emissions than AEO 2017 projections; the combination of the IET's current stock turnover and energy efficiency assumptions is the likely source of these differences.

The open-source nature of the IET tool and its data foundation means they are intended to be revised and improved over time by a community of users. Identified improvements to the IET would improve its foundational data, provide new functionality, and create a better user experience. In combination with the tool's current capabilities, the improvements would offer more ways for analysts and policymakers to understand energy use in the U.S. industrial sector. 


\section{References}

Brown, Elizabeth, and R. Neal Elliott. 2005. “On-Farm Energy Use Characterizations.” IE052. Washington, D.C.: American Council for an Energy-Efficient Economy. http://aceee.org/sites/default/files/publications/researchreports/ie052.pdf.

Brown, Harry L., Bernard B. Hamel, and Bruce A. Hedman. 1997. Energy Analysis of 108 Industrial Processes. Prentice Hall.

DOE (U.S. Department of Energy). 2007. "Mining Industry Energy Bandwidth Study." Washington, D.C.: U.S. Department of Energy Industrial Technologies Program. http://www.energy.gov/eere/amo/downloads/us-mining-industry-energy-bandwidth-study.

- 2015a. "Bandwidth Study on Energy Use and Potential Energy Saving Opportunities in U.S. Chemical Manufacturing." Washington, D.C.: U.S. Department of Energy Energy Efficiency and Renewable Energy. http://energy.gov/eere/amo/downloads/bandwidth-study-uschemical-manufacturing.

- 2015b. "Bandwidth Study on Energy Use and Potential Energy Saving Opportunities in U.S. Iron and Steel Manufacturing." Washington, D.C.: U.S. Department of Energy Energy Efficiency and Renewable Energy. http://energy.gov/eere/amo/downloads/bandwidth-study-usiron-and-steel-manufacturing.

- 2015c. "Bandwidth Study on Energy Use and Potential Energy Saving Opportunities in U.S. Petroleum Refining." Washington, D.C.: U.S. Department of Energy Energy Efficiency and Renewable Energy. http://energy.gov/eere/amo/downloads/bandwidth-study-us-petroleumrefining.

- 2015d. "Bandwidth Study on Energy Use and Potential Energy Saving Opportunities in U.S. Pulp and Paper Manufacturing." Washington, D.C.: U.S. Department of Energy Energy Efficiency and Renewable Energy. http://energy.gov/eere/amo/downloads/bandwidth-study-uspulp-and-paper-manufacturing.

- 2017a. "Bandwidth Study on Energy Use and Potential Energy Saving Opportunities in U.S. Aluminum Manufacturing." Washington, D.C.: U.S. Department of Energy Office of Energy Efficiency and Renewable Energy. https://www.energy.gov/eere/amo/downloads/bandwidth-study-us-aluminum-manufacturing.

- 2017b. "Bandwidth Study on Energy Use and Potential Energy Saving Opportunities in U.S. Magnesium Manufacturing.” Washington, D.C.: U.S. Department of Energy Energy Efficiency and Renewable Energy. https://www.energy.gov/eere/amo/downloads/bandwidthstudy-us-magnesium-manufacturing.

- 2017c. "Bandwidth Study on Energy Use and Potential Energy Savings Opportunities in U.S. Cement Manufacturing." Washington, D.C.: U.S. Department of Energy Energy Efficiency and Renewable Energy. https://www.energy.gov/eere/amo/downloads/bandwidth-study-uscement-manufacturing. 
- 2017d. "Bandwidth Study on Energy Use and Potential Energy Savings Opportunities in U.S. Food and Beverage Manufacturing." Washington, D.C.: U.S. Department of Energy Energy Efficiency and Renewable Energy. https://www.energy.gov/eere/amo/downloads/bandwidthstudy-us-food-and-beverage-manufacturing.

. 2017e. "Bandwidth Study on Energy Use and Potential Energy Savings Opportunities in U.S. Glass Manufacturing." Washington, D.C.: U.S. Department of Energy Office of Energy Efficiency and Renewable Energy. https:/www.energy.gov/eere/amo/downloads/bandwidthstudy-us-glass-manufacturing.

_. 2017f. "Bandwidth Study on Energy Use and Potential Energy Savings Opportunities in U.S. Plastics and Rubber Manufacturing." Washington, D.C.: U.S. Department of Energy Energy Efficiency and Renewable Energy. https:/www.energy.gov/eere/amo/downloads/bandwidthstudy-us-plastics-and-rubber-manufacturing.

_.2017g. "Bandwidth Study on Energy Use and Potential Energy Savings Opportunities in U.S. Titanium Manufacturing." Washington, D.C.: U.S. Department of Energy Energy Efficiency and Renewable Energy. https://www.energy.gov/eere/amo/downloads/bandwidthstudy-us-titanium-manufacturing.

- n.d. "Bandwidth Studies." Energy Analysis by Sector. Accessed September 7, 2016. http://energy.gov/eere/amo/energy-analysis-sector\#5.

EIA (Energy Information Administration). 2002. “2002 MECS Survey Data.” Manufacturing Energy Consumption Survey (MECS). 2002.

https:/www.eia.gov/consumption/manufacturing/data/2002/index.php? view=methodology.

- 2009. "Selected Survey Attributes of the Manufacturing Energy Consumption Survey (MECS).” MECS Attributes. June 2009.

https://www.eia.gov/consumption/manufacturing/reports/archive/attributes/mecs attributes.html.

—. 2013. "2010 MECS Survey Data.” Manufacturing Energy Consumption Survey

(MECS). 2013. http://www.eia.gov/consumption/manufacturing/data/2010/.

- 2014. "Assumptions to the Annual Energy Outlook 2014.” Washington, D.C.:

U.S. Energy Information Administration.

https://www.eia.gov/outlooks/archive/aeo14/assumptions/pdf/0554(2014).pdf.

—. 2016. “Annual Energy Outlook 2016.” Washington, D.C.

http://www.eia.gov/forecasts/aeo/.

—. 2017a. “Annual Energy Outlook 2017.” Annual Energy Outlook. Washington, D.C.:

U.S. Energy Information Administration. https://www.eia.gov/outlooks/aeo/pdf/0383(2017).pdf.

_. 2017b. “Annual Electric Utility Data: EIA-906/920/923 Data File.” Electricity. 2017. https://www.eia.gov/electricity/data/eia923/.

- 2017c. "MECS Terminology.” Manufacturing Energy Consumption Survey (MECS). 2017. https://www.eia.gov/consumption/manufacturing/terms.php. 
_. 2017d. "Retail Sales of Electricity to Ultimate Customers." Electricity. 2017. https://www.eia.gov/electricity/data.php\#sales.

_. 2017e. "Natural Gas Prices.” Natural Gas. 2017. https://www.eia.gov/dnav/ng/ng_pri_sum_dcu_nus_m.htm.

_. 2017f. “2014 MECS Survey Data.” Manufacturing Energy Consumption Survey (MECS) - Data - U.S. Energy Information Administration (EIA). 2017. https://www.eia.gov/consumption/manufacturing/data/2014/.

—. 2017g. "State Energy Data System (SEDS)." 2017. https://www.eia.gov/state/seds/. —. 2017h. "Assumptions to the Annual Energy Outlook 2017.” Washington, D.C.: Energy Information Administration. https://www.eia.gov/outlooks/aeo17/assumptions/pdf/industrial.pdf.

—. 2018a. "Monthly Energy Review.” Energy Consumption by Sector. 2018. http://www.eia.gov/totalenergy/data/monthly/\#consumption.

—. 2018b. “Annual Energy Outlook 2018.” Annual Energy Outlook. Washington, D.C.: Energy Information Administration. https://www.eia.gov/outlooks/aeo/.

- 2018c. "Consumption \& Efficiency." Data. 2018.

https://www.eia.gov/consumption/data.php.

_. 2018d. "Model Documentation Report: Industrial Demand Module of the National Energy Modeling System." Washington, D.C.: U.S. Energy Information Administration. https://www.eia.gov/outlooks/aeo/nems/documentation/industrial/pdf/m064(2016).pdf.

—. 2018e. "Environment." 2018. https://www.eia.gov/environment/data.php.

EMF (Energy Modeling Forum). 1987. "Final Summary Report for EMF 8: Industrial Energy Demand.” Energy Modeling Forum. Stanford, CA: Stanford University. https://web.stanford.edu/group/emf-research/docs/emf8/8v1.pdf.

EPA (U.S. Environmental Protection Agency). 2014. "EGRID Power Profiler Emissions Tool.” https://www.epa.gov/sites/production/files/2017-

05/power_profiler_zipcode tool_2014_v7.1_1.xlsx.

—. 2018. "Emission Factors for Greenhouse Gas Inventories." EPA Center for Climate Leadership. March 9, 2018. https://www.epa.gov/sites/production/files/2018-

03/documents/emission-factors_mar_2018_0.pdf.

EPA, OAR. 2017. “Greenhouse Gas Reporting Program (GHGRP).” Policies and Guidance. U.S. EPA. 2017. https://www.epa.gov/ghgreporting.

Evolved Energy Research. 2018. EnergyPATHWAYS. Python. EnergyPATHWAYS. https://github.com/energyPATHWAYS/EnergyPATHWAYS.

Fais, Birgit, Nagore Sabio, and Neil Strachan. 2016. "The Critical Role of the Industrial Sector in Reaching Long-Term Emission Reduction, Energy Efficiency and Renewable Targets." Applied Energy 162 (Supplement C): 699-712. https://doi.org/10.1016/j.apenergy.2015.10.112. 
Fleiter, Tobias, Ernst Worrell, and Wolfgang Eichhammer. 2011. "Barriers to Energy Efficiency in Industrial Bottom-up Energy Demand Models-A Review." Renewable and Sustainable Energy Reviews 15 (6): 3099-3111. https://doi.org/10.1016/j.rser.2011.03.025.

Fox, Don B., Daniel Sutter, and Jefferson W. Tester. 2011. "The Thermal Spectrum of LowTemperature Energy Use in the United States.” Ithaca, NY: Cornell Energy Institute.

Hannon, B. M., R. G. Stein, B. Z. Segal, and D. Serber. 1977. "Energy Use for Building Construction: Final Report.” COO-2791-3. Champaign, IL: Energy Research Group, Center for Advanced Computation :

https://www.ideals.illinois.edu/bitstream/handle/2142/32914/energyuseforbuil228hanno.pdf.

Hannon, B. M., R. G. Stein, B. Z. Segal, D. Serber, P. F. Diebert, M. Buckley, and D. Nathan. 1977. "Energy Use for Building Construction: Supplement." COO-2791-4. Champaign, IL: Energy Research Group, Center for Advanced Computation : https:/www.ideals.illinois.edu/bitstream/handle/2142/32542/energyuseforbuil228hann.pdf.

Lempert, Robert J., Steven W. Popper, Susan A. Resetar, and Stuart L. Hart. 2002. "Capital Cycles and the Timing of Climate Change Policy." Arlington, VA: Pew Center on Global Climate Change. http://www.c2es.org/publications/capital-cycles-and-timing-climate-changepolicy.

Ludington, David, and Eric L Johnson. 2003. "Dairy Farm Energy Audit Summary." Albany, NY: New York State Energy Research and Development Authority. https://www.nyserda.ny.gov/-/media/Files/Publications/Research/Energy-Audit-Reports/dairyfarm-energy.pdf.

Mandatory Greenhouse Gas Reporting. 2009. Code of Federal Regulations. Vol. 40. http://www.ecfr.gov/cgi-bin/text-idx?tpl=/ecfrbrowse/Title40/40cfr98 main_02.tpl.

McMillan, Colin. 2018. "Material and Energy Efficiency: A Framework for Broader Analysis of Energy Use in the U.S. Economy." NREL/TP-6A20-70609. Golden, CO: National Renewable Energy Laboratory. https://www.nrel.gov/docs/fy18osti/70609.pdf.

McMillan, Colin, Richard Boardman, Michael McKellar, Piyush Sabharwall, Mark Ruth, and Shannon Bragg-Sitton. 2016. "Generation and Use of Thermal Energy in the U.S. Industrial Sector and Opportunities to Reduce Its Carbon Emissions." NREL/TP-6A50-66763; INL/EXT16-39680. Golden, CO: National Renewable Energy Laboratory. doi:10.2172/1334495.

Miller, Ronald E., and Peter D. Blair. 2009. Input-Output Analysis: Foundations and Extensions. Cambridge University Press.

Saygin, D., E. Worrell, C. Tam, N. Trudeau, D. J. Gielen, M. Weiss, and M. K. Patel. 2012. "Long-Term Energy Efficiency Analysis Requires Solid Energy Statistics: The Case of the German Basic Chemical Industry." Energy, Integration and Energy System Engineering, European Symposium on Computer-Aided Process Engineering 2011, 44 (1): 1094-1106. https://doi.org/10.1016/j.energy.2012.01.062. 
Stein, R. G., C. Stein, M. Buckley, and M. Green. 1980. "Handbook of Energy Use for Building Construction.” DOE/CS/20220-1. U.S. Department of Energy.

https://www.osti.gov/scitech/biblio/5190332.

The Minnesota Project. 2015. "Dairy Energy Efficiency: Dairy Cooperative Partnerships for Improved Efficiency Program Adoption.” COMM-03192012-55635|. St. Paul, MN: Minnesota Department of Commerce Division of Energy Resources. http://mn.gov/commercestat/pdfs/card-report-tmp-dairy-ee.pdf.

USDA (U.S. Department of Agriculture). 2017. "USDA-NASS, Census of Agriculture: Publications, 2012.” 2012 Census Publications. June 16, 2017. https://www.agcensus.usda.gov/Publications/2012/.

USDA Economic Research Service. 2018. "Production Expenses by Type, State Ranking." Electricity. August 30, 2018. https://data.ers.usda.gov/reports.aspx?ID=17842\#P9e6dd64ba85c45f5827765b3320f725b 2 252 iT0R0x17.

USDA National Agricultural Statistics Service. 2018. “USDA/NASS QuickStats.” Quick Stats. 2018. https://quickstats.nass.usda.gov/?source desc=CENSUS.

USGS (United States Geological Survey). 2016. "USGS Minerals Information:

Commodity Statistics and Information.” December 19, 2016.

https://minerals.usgs.gov/minerals/pubs/commodity/.

U.S. Bureau of the Census. 2009. "The Researcher Handbook." The Researcher Handbook

U.S. Bureau of the Census Center for Economic Studies.

https://www.census.gov/content/dam/Census/programs-

surveys/sipp/methodology/Researcher_Handbook_20091119.pdf.

U.S. Census Bureau. 2016. “County Business Patterns: 2014.” Data. April 24, 2016.

http://www.census.gov/data/datasets/2014/econ/cbp/2014-cbp.html.

_ 2018. "US Census Bureau Center for Economic Studies Data Products Page.” April 5, 2018. https://www.census.gov/ces/dataproducts/public data.html.

“USEEIO Input-Output Accounts.” 2017. Data.Gov. February 10, 2017. https://catalog.data.gov/dataset/useeio-input-output-accounts.

Worrell, Ernst, Stephan Ramesohl, and Gale Boyd. 2004. "Advances in Energy Forecasting Models Based on Engineering Economics." Annual Review of Environment and Resources 29 (1): 345-81. https://doi.org/10.1146/annurev.energy.29.062403.102042.

Yang, Yi, Wesley W. Ingwersen, Troy R. Hawkins, Michael Srocka, and David E. Meyer. 2017. "USEEIO: A New and Transparent United States Environmentally-Extended Input-Output Model." Journal of Cleaner Production 158 (Supplement C): 308-18. https://doi.org/10.1016/j.jclepro.2017.04.150. 


\section{Appendix A. Dynamic Hybrid Input-Output Module}

The purpose of the input-output (IO) module is to evaluate the effects of stock turnover, change in material efficiency, and fuel switching on interindustry trade, emissions, and energy use within the U.S. economy.

The IO model is based on the USEEIO Model published by the EPA (Yang et al. 2017; "USEEIO Input-Output Accounts" 2017), which specifies detailed commodity outputs and use on a level of six-digit NAICS code for 2013 in monetary units (389 x 389 matrix). The six-digit NAICS codes were mapped to the U.S. Bureau of Economic Analysis (BEA) IO codes, and the values having the same BEA IO codes were summed to obtain new make and use tables $(78 \times 78$ matrices). The fractional distribution of outputs and use for all the sectors was calculated, and the resulting value could then be used to obtain the make and use tables for 2014 .

The BEA prepared statistics for make and use tables after redefinitions data from the IO accounts for 1997-2015. These data are available in the form of $71 \times 71$ matrices. The data for 2014 were then multiplied by the fractions to obtain a more detailed version of the $78 \times 78$ matrix.

The interindustry transaction matrix can be obtained as follows (Miller and Blair, 2014):

If $\mathrm{U}$ is considered parallel to $\mathrm{Z}$, the matrix $\mathrm{B}$ parallel to A can be obtained as:

$$
B=U \cdot\left(x_{-} \operatorname{cap}\right)-1
$$

Similarly, if $\mathrm{V}$ is considered parallel to $\mathrm{Z}$, the matrix parallel to A can be obtained as:

$$
\begin{aligned}
& D=V \cdot\left(q_{-} \text {cap }\right)^{-1} \\
& A=B \cdot D \\
& Z=A \cdot\left(x_{-} \text {cap }\right)^{-1} \\
& L=(I-A)^{-1} \\
& f=x-m
\end{aligned}
$$

Where:

$\mathrm{V}=$ make matrix

$\mathrm{U}=$ use matrix

$\mathrm{Z}=$ interindustry transactions matrix

$\mathrm{x}=$ total industry outputs vector

$\mathrm{f}=$ total final demands vector

$\mathrm{q}=$ total commodity output vector

$\mathrm{A}=$ direct input coefficients

$\mathrm{L}=$ Leontief inverse

x_cap,q_cap,f_cap $=$ diagonal

matrices having $\mathrm{x}, \mathrm{q}$ and $\mathrm{f}$ vectors as diagonal elements

\section{A.1 Hybrid IO Model}

Defining energy use and production in physical units instead of monetary units maintains an energy balance and helps avoid issues associated with heterogenous fuel prices (Miller and Blair 2009). For example, commodities are sold at wholesale and retail rates depending on the consumer. Consider electricity: it is sold at lower rates to the industrial sector than to the residential sector. Thus, measuring the value of such commodities in dollars (or any other currency) would imply overestimation in the retail sector and underestimation in the wholesale sector. So, we used a hybrid interindustry transaction matrix with energy sectors measured in physical units and all other sectors in monetary units. 
The approach was adopted from Miller and Blair (2014). In this approach, we tried to create corresponding hybrid matrices to account for the interindustry transactions ( $Z$ _hybrid), direct input coefficients (A_hybrid) and the total requirements (L_hybrid). Z hybrid matrix is obtained by taking the original interindustry transactions matrix and replacing the rows representing the energy flows in dollars with the rows representing the same commodities in the energy flow matrix, E. Thus Z-hybrid has energy flows represented in energy units and the flow of other commodities represented in dollars. Similarly, the vectors corresponding to total output (x_hybrid) and final demand (f_hybrid) are obtained in hybrid units. The matrix notations are summarized as:

$$
\begin{gathered}
Z_{\text {hybrid }}=\left[z_{i j}\right]=\left\{\begin{array}{l}
z_{i j} \text { where } i \text { is a non }- \text { energy sector } \\
e_{k j} \text { where } k \text { is an energy sector }
\end{array}\right. \\
x_{\text {hybrid }}=\left[x_{i}\right]=\left\{\begin{array}{l}
x_{i} \text { where } i \text { is a non }- \text { energy sector } \\
g_{k} \text { where } k \text { is an energy sector }
\end{array}\right. \\
f_{\text {hybrid }}=\left[f_{i}\right]=\left\{\begin{array}{l}
f_{i} \text { where } i \text { is a non }- \text { energy sector } \\
q_{k} \text { where } k \text { is an energy sector }
\end{array}\right. \\
g_{\text {hybrid }}=\left[g_{i}\right]=\left\{\begin{array}{l}
0 \text { where } i \text { is a non }- \text { energy sector } \\
g_{k} \text { where } k \text { is an energy sector }
\end{array}\right.
\end{gathered}
$$

Total energy used by fuel types for all the sectors was obtained from AEO 2017 (EIA 2017a). The fractional distribution of the energy values was assumed equal to the fractional distribution of monetary values for a given sector. The total energy use of a sector was then multiplied by the fractional values to obtain the energy used by fuel type on a six-digit NAICS code level (389 industries). This was again mapped to the BEA IO codes (78 industries). The energy commodity rows in the $\mathrm{Z}$ matrix were then replaced by these values to obtain $Z_{-}$hybrid matrix.

The matrices A_hybrid and L_hybrid can be obtained as follows:

$$
\begin{gathered}
A_{\text {hybrid }}=Z_{\text {hybrid }}\left(\hat{x}_{\text {hybrid }}\right)^{-1} \\
L_{\text {hybrid }}=\left(I-A_{\text {hybrid }}\right)^{-1}
\end{gathered}
$$

\section{A.2 RAS Algorithm}

The construction of an IO table for any country requires detailed surveys to calculate the input and the output of each sector. The results of these surveys are not available immediately (and sometimes not for five years) due to the need to process the information, and debug the inconsistencies. As such, constructing and updating the IO table can be time consuming. However, a parameter estimation technique can be used to predict the values of a new IO matrix using an old IO matrix if partial information such as the final demands of commodities for the current year are known. One such technique to achieve this is the RAS algorithm (Miller and Blair 2014).

The approach taken with the IET was adopted from Miller and Blair (2014). Consider a detailed IO table for a past year ("0") and that we want to apply the parameter estimation technique to it 
to obtain the IO table for current year (" 1 "); that is, we have $A(0)$ and we want $A(1)$. To apply the parameter estimation technique, we would require some information for the current year. The RAS algorithm requires " $3 n$ " pieces of information for the current year for a " $n$ " sector economy:

- Total gross output, $\mathrm{x}_{\mathrm{j}}$

- Total interindustry sales by sector

- Total interindustry purchases by sector.

The procedure can be explained with a $3 \times 3$ matrix. The potential usefulness of the technique is in real-world applications, where the number of sectors is much larger than three and hence the difference between $\mathrm{n}^{2}$ and $3 \mathrm{n}$ is large. In the IET, we consider a 78-sector economy, $\mathrm{n}^{2}=6,084$, whereas $3 n=234$. The usefulness of RAS can be seen from the fact that to update 6,084 elements we need information for just 234 elements.

For the general $3 \times 3$ case, assume that base-year coefficients are known.

$$
A(0)=\left[\begin{array}{lll}
a 11(0) & a 12(0) & a 13(0) \\
a 21(0) & a 22(0) & a 23(0) \\
a 31(0) & a 32(0) & a 33(0)
\end{array}\right]
$$

For the target year 1, following data are known:

$$
x(1)=\left[\begin{array}{l}
x 1(1) \\
x 2(1) \\
x 3(1)
\end{array}\right] \quad u(1)=\left[\begin{array}{l}
u 1(1) \\
u 2(1) \\
u 3(1)
\end{array}\right] \quad v(1)=\left[\begin{array}{l}
v 1(1) \\
v 2(1) \\
v 3(1)
\end{array}\right]
$$

Initially it is assumed $\mathrm{A}(0)=\mathrm{A}(1)$.

$$
\begin{gathered}
Z=A(0) \cdot x(1) \_c a p \\
Z=\left[\begin{array}{lll}
a 11(0) \cdot x 1(1) & a 12(0) \cdot x 2(1) & a 13(0) \cdot x 3(1) \\
a 21(0) \cdot x 1(1) & a 22(0) \cdot x 2(1) & a 23(0) \cdot x 3(1) \\
a 31(0) \cdot x 1(1) & a 32(0) \cdot x 2(1) & a 33(0) \cdot x 3(1)
\end{array}\right]
\end{gathered}
$$

The vector $u$ for this matrix is the row sum and the vector $v$ is the column sum. For most of the cases, these values will not be equal to $u(1)$ and $v(1)$ respectively.

$$
\begin{aligned}
& a 11(0) \cdot x 1(1)+a 12(0) \cdot x 2(1)+a 13(0) \cdot x 3(1)=u 1 \neq u 1(1) \\
& a 21(0) \cdot x 1(1)+a 22(0) \cdot x 2(1)+a 23(0) \cdot x 3(1)=u 2 \neq u 2(1) \\
& a 31(0) \cdot x 1(1)+a 32(0) \cdot x 2(1)+a 33(0) \cdot x 3(1)=u 3 \neq u 3(1)
\end{aligned}
$$

Premultiplying the matrix $\mathrm{A}(0)$ by a matrix $\mathrm{R}$ such that: 


$$
R=\left[\begin{array}{ccc}
u 1(1) / u 1 & 0 & 0 \\
0 & u 2(1) / u 2 & 0 \\
0 & 0 & u 3(1) / u 3
\end{array}\right]
$$

Now, considering $A(1)=R \cdot A(0)$ and $Z=A(1) . x(1)$ cap, the row sum of $Z$ matrix is equal to the $\mathrm{u}(1)$ vector. However, the column sum is not equal to the $\mathrm{v}(1)$ vector.

$$
\begin{aligned}
& a 11(1) \cdot x 1(1)+a 21(1) \cdot x 1(1)+a 31(1) \cdot x 1(1)=v 1 \neq v 1(1) \\
& a 12(1) \cdot x 2(1)+a 22(1) \cdot x 2(1)+a 32(1) \cdot x 2(1)=v 2 \neq v 2(1) \\
& a 13(1) \cdot x 3(1)+a 23(1) \cdot x 3(1)+a 33(1) \cdot x 3(1)=v 3 \neq v 3(1)
\end{aligned}
$$

Postmultiplying the current $\mathrm{A}(1)$ matrix by a matrix S such that:

$$
S=\left[\begin{array}{ccc}
v 1(1) / v 1 & 0 & 0 \\
0 & v 2(1) / v 2 & 0 \\
0 & 0 & v 3(1) / v 3
\end{array}\right]
$$

Now,

$$
A(1)=R A S
$$

The $\mathrm{Z}$ matrix obtained from these coefficients will have a column sum equal to the v(1) vector. However, the row sum is disturbed and is not equal to the $u(1)$ vector. The procedure is repeated until the column sum and row sum obtained from the $\mathrm{Z}$ matrix are equal to the $\mathrm{v}(1)$ and $\mathrm{u}(1)$ vectors respectively. We considered convergence of the order of 0.001 instead of to zero to speed the calculations. 


\section{Appendix B. Comparison of IET Foundational Data and EIA State Energy Data System (SEDS)}

The following figure and table aggregate the IET county-level industrial energy use data to the state level to compare against EIA SEDS. The IET fuel types have also been aggregated to match the categories used by SEDS. Negative values indicate an IET value less than SEDS; positive values indicate an IET value greater than SEDS.

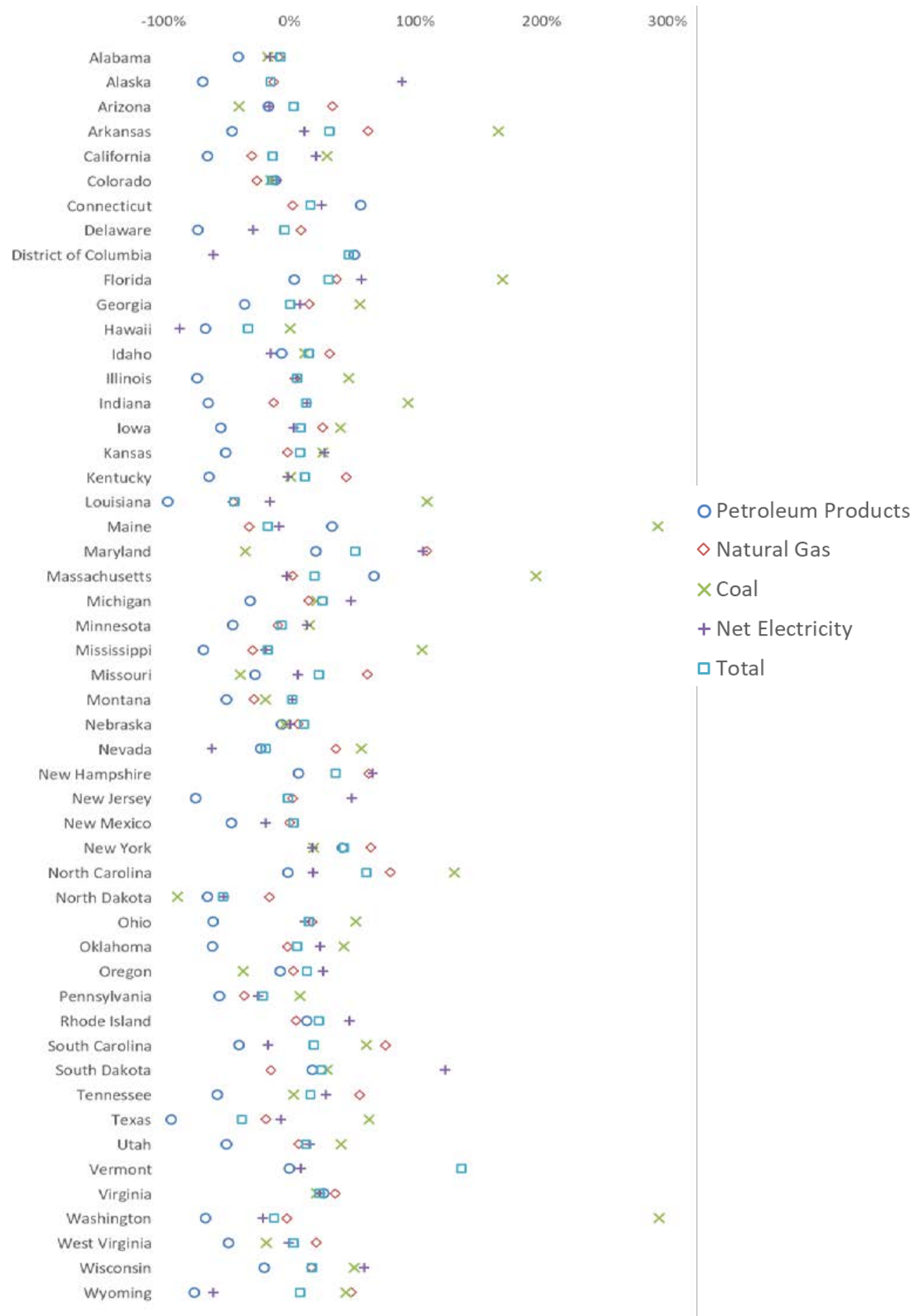

Figure 18. Relative difference between state-aggregated IET foundational data and SEDS, by fuel

Values above $300 \%$ and where SEDS values are zero are excluded. 
Table 9. Comparison of State-Level Aggregated IET Foundational Data and SEDS

\begin{tabular}{|c|c|c|c|c|c|c|c|c|c|c|}
\hline \multirow[t]{2}{*}{ State } & \multicolumn{2}{|c|}{$\begin{array}{l}\text { Petroleum } \\
\text { Products }\end{array}$} & \multicolumn{2}{|c|}{ Natural Gas } & \multicolumn{2}{|l|}{ Coal } & \multicolumn{2}{|c|}{ Net Electricity } & \multicolumn{2}{|l|}{ Total } \\
\hline & TBtu & $\%$ & TBtu & $\%$ & TBtu & $\%$ & TBtu & $\%$ & TBtu & $\%$ \\
\hline Alabama & -16 & $-40 \%$ & -17 & $-8 \%$ & -7 & $-17 \%$ & -18 & $-15 \%$ & -39 & $-7 \%$ \\
\hline Alaska & -28 & $-68 \%$ & -31 & $-12 \%$ & 1 & $7,756 \%$ & 4 & $89 \%$ & -44 & $-14 \%$ \\
\hline Arizona & -6 & $-16 \%$ & 8 & $34 \%$ & -2 & $-39 \%$ & -8 & $-16 \%$ & 4 & $4 \%$ \\
\hline Arkansas & -22 & $-45 \%$ & 61 & $63 \%$ & 9 & $166 \%$ & 7 & $12 \%$ & 90 & $32 \%$ \\
\hline California & -229 & $-65 \%$ & -252 & $-29 \%$ & 10 & $30 \%$ & 39 & $21 \%$ & -190 & $-13 \%$ \\
\hline Colorado & -5 & $-11 \%$ & -48 & $-25 \%$ & -1 & $-15 \%$ & -5 & $-10 \%$ & -39 & $-13 \%$ \\
\hline Connecticut & 4 & $57 \%$ & 1 & $3 \%$ & 1 & & 3 & $26 \%$ & 9 & $17 \%$ \\
\hline Delaware & -19 & $-72 \%$ & 3 & $9 \%$ & 0 & & -2 & $-29 \%$ & -2 & $-4 \%$ \\
\hline $\begin{array}{l}\text { District of } \\
\text { Columbia }\end{array}$ & 0 & $52 \%$ & 1 & & 0 & & 0 & $-60 \%$ & 1 & $48 \%$ \\
\hline Florida & 3 & $4 \%$ & 37 & $38 \%$ & 27 & $169 \%$ & 32 & $58 \%$ & 107 & $32 \%$ \\
\hline Georgia & -20 & $-35 \%$ & 26 & $16 \%$ & 12 & $57 \%$ & 9 & $9 \%$ & 4 & $1 \%$ \\
\hline Hawaii & -12 & $-66 \%$ & 4 & $955 \%$ & 0 & $1 \%$ & -11 & $-86 \%$ & -12 & $-32 \%$ \\
\hline Idaho & -1 & $-6 \%$ & 9 & $32 \%$ & 1 & $12 \%$ & -5 & $-15 \%$ & 17 & $16 \%$ \\
\hline Illinois & -170 & $-73 \%$ & 15 & $5 \%$ & 31 & $47 \%$ & 9 & $6 \%$ & 50 & $7 \%$ \\
\hline Indiana & -68 & $-64 \%$ & -46 & $-12 \%$ & 44 & $94 \%$ & 23 & $14 \%$ & 96 & $13 \%$ \\
\hline lowa & -55 & $-54 \%$ & 48 & $27 \%$ & 24 & $41 \%$ & 3 & $4 \%$ & 38 & $9 \%$ \\
\hline Kansas & -34 & $-50 \%$ & -2 & $-1 \%$ & 1 & $27 \%$ & 11 & $28 \%$ & 21 & $9 \%$ \\
\hline Kentucky & -67 & $-63 \%$ & 57 & $45 \%$ & 0 & $2 \%$ & -1 & $-1 \%$ & 49 & $13 \%$ \\
\hline Louisiana & -879 & $-96 \%$ & -506 & $-44 \%$ & 3 & $109 \%$ & -18 & $-15 \%$ & $-1,001$ & $-43 \%$ \\
\hline Maine & 2 & $34 \%$ & -8 & $-31 \%$ & 2 & $292 \%$ & -1 & $-8 \%$ & -18 & $-17 \%$ \\
\hline Maryland & 4 & $22 \%$ & 17 & $109 \%$ & -5 & $-35 \%$ & 14 & $106 \%$ & 36 & $52 \%$ \\
\hline $\begin{array}{l}\text { Massachuset } \\
\text { ts }\end{array}$ & 8 & $67 \%$ & 1 & $3 \%$ & 3 & $196 \%$ & -1 & $-2 \%$ & 19 & $20 \%$ \\
\hline Michigan & -18 & $-31 \%$ & 30 & $16 \%$ & 6 & $22 \%$ & 54 & $49 \%$ & 117 & $26 \%$ \\
\hline Minnesota & -46 & $-45 \%$ & -15 & $-9 \%$ & 4 & $17 \%$ & 11 & $14 \%$ & -24 & $-6 \%$ \\
\hline Mississippi & -41 & $-68 \%$ & -35 & $-29 \%$ & 3 & $106 \%$ & -10 & $-19 \%$ & -49 & $-17 \%$ \\
\hline Missouri & -13 & $-27 \%$ & 42 & $62 \%$ & -9 & $-38 \%$ & 4 & $7 \%$ & 48 & $24 \%$ \\
\hline
\end{tabular}




\begin{tabular}{|c|c|c|c|c|c|c|c|c|c|c|}
\hline \multirow[t]{2}{*}{ State } & \multicolumn{2}{|c|}{$\begin{array}{l}\text { Petroleum } \\
\text { Products }\end{array}$} & \multicolumn{2}{|c|}{ Natural Gas } & \multicolumn{2}{|l|}{ Coal } & \multicolumn{2}{|c|}{ Net Electricity } & \multicolumn{2}{|l|}{ Total } \\
\hline & TBtu & $\%$ & TBtu & $\%$ & TBtu & $\%$ & TBtu & $\%$ & TBtu & $\%$ \\
\hline Montana & -19 & $-50 \%$ & -7 & $-28 \%$ & -1 & $-18 \%$ & 0 & $3 \%$ & 2 & $3 \%$ \\
\hline Nebraska & -2 & $-6 \%$ & 7 & $8 \%$ & -1 & $-4 \%$ & 0 & $1 \%$ & 21 & $12 \%$ \\
\hline Nevada & -5 & $-22 \%$ & 6 & $37 \%$ & 4 & $57 \%$ & -29 & $-61 \%$ & -17 & $-18 \%$ \\
\hline $\begin{array}{l}\text { New } \\
\text { Hampshire }\end{array}$ & 0 & $8 \%$ & 6 & $63 \%$ & 0 & & 4 & $66 \%$ & 9 & $37 \%$ \\
\hline New Jersey & -75 & $-74 \%$ & 2 & $3 \%$ & 9 & & 13 & $49 \%$ & -2 & $-1 \%$ \\
\hline New Mexico & -14 & $-46 \%$ & 0 & $0 \%$ & 10 & $682 \%$ & -5 & $-18 \%$ & 6 & $4 \%$ \\
\hline New York & 17 & $43 \%$ & 57 & $65 \%$ & 3 & $20 \%$ & 12 & $19 \%$ & 99 & $44 \%$ \\
\hline $\begin{array}{l}\text { North } \\
\text { Carolina }\end{array}$ & 0 & $-1 \%$ & 89 & $80 \%$ & 21 & $131 \%$ & 18 & $19 \%$ & 209 & $61 \%$ \\
\hline $\begin{array}{l}\text { North } \\
\text { Dakota }\end{array}$ & -54 & $-65 \%$ & -7 & $-15 \%$ & -82 & $-88 \%$ & -13 & $-52 \%$ & -132 & $-52 \%$ \\
\hline Ohio & -82 & $-60 \%$ & 59 & $18 \%$ & 17 & $53 \%$ & 21 & $12 \%$ & 111 & $16 \%$ \\
\hline Oklahoma & -57 & $-61 \%$ & -3 & $-1 \%$ & 6 & $43 \%$ & 15 & $25 \%$ & 30 & $6 \%$ \\
\hline Oregon & -2 & $-7 \%$ & 2 & $3 \%$ & -1 & $-36 \%$ & 12 & $27 \%$ & 23 & $14 \%$ \\
\hline Pennsylvania & -94 & $-55 \%$ & -148 & $-35 \%$ & 3 & $9 \%$ & -40 & $-25 \%$ & -175 & $-21 \%$ \\
\hline Rhode Island & 0 & $14 \%$ & 0 & $6 \%$ & 0 & & 1 & $48 \%$ & 3 & $23 \%$ \\
\hline $\begin{array}{l}\text { South } \\
\text { Carolina }\end{array}$ & -13 & $-40 \%$ & 65 & $77 \%$ & 9 & $61 \%$ & -17 & $-17 \%$ & 64 & $20 \%$ \\
\hline South Dakota & 3 & $18 \%$ & -7 & $-15 \%$ & 1 & $30 \%$ & 12 & $124 \%$ & 19 & $26 \%$ \\
\hline Tennessee & -35 & $-57 \%$ & 68 & $56 \%$ & 2 & $3 \%$ & 24 & $29 \%$ & 64 & $17 \%$ \\
\hline Texas & $-2,486$ & $-94 \%$ & -377 & $-18 \%$ & 17 & $63 \%$ & -23 & $-6 \%$ & $-1,938$ & $-37 \%$ \\
\hline Utah & -21 & $-50 \%$ & 6 & $8 \%$ & 6 & $41 \%$ & 6 & $17 \%$ & 22 & $14 \%$ \\
\hline Vermont & 0 & $0 \%$ & 8 & $420 \%$ & 1 & & 0 & $9 \%$ & 16 & $137 \%$ \\
\hline Virginia & 8 & $27 \%$ & 34 & $36 \%$ & 6 & $22 \%$ & 15 & $25 \%$ & 66 & $24 \%$ \\
\hline Washington & -71 & $-66 \%$ & -1 & $-2 \%$ & 8 & $294 \%$ & -20 & $-21 \%$ & -44 & $-12 \%$ \\
\hline West Virginia & -22 & $-48 \%$ & 18 & $22 \%$ & -4 & $-18 \%$ & 0 & $0 \%$ & 8 & $4 \%$ \\
\hline Wisconsin & -10 & $-20 \%$ & 26 & $18 \%$ & 17 & $52 \%$ & 48 & $59 \%$ & 67 & $18 \%$ \\
\hline Wyoming & -42 & $-75 \%$ & 49 & $50 \%$ & 14 & $45 \%$ & -21 & $-60 \%$ & 20 & $9 \%$ \\
\hline
\end{tabular}




\section{Appendix C. Energy Efficiency Assumptions}

Table C-1 lists all efficiency assumptions used by the IET. Efficiency is expressed as the reduction in 2050 energy use relative to 2014 energy use. So, for example, the first row of the table identifies that the state-of-art opportunity (SOA_opp) for NAICS code 31212 in 2050 is a reduction of $17.9 \%$ from 2014 energy use. The assumptions may be referred to in slightly different fashions in the bandwidth reports:

- SOA_opp: the efficiency improvement achieved by reducing current typical energy consumption (i.e., 2014 baseline energy use) to state-of-the-art energy consumption; also referred to as current opportunity by bandwidth studies

- R\&D_opp: the energy efficiency improvement achieved by reducing state-of-the-art energy consumption to practical minimum energy consumption

- PM_opp: the efficiency improvement achieved by reducing current typical energy consumption to practical minimum energy consumption; PM_opp is the sum of SOA_opp and R\&D_opp. Certain bandwidth studies included estimates for low and high practical minimum energy consumption, which are captured as efficiency improvements in Table B1 as PM_low and PM_high respectively.

Table C-1. Bandwidth Efficiency Data Assumptions by NAICS Code (Assumed Reduction in 2050 Energy Use Relative to 2014)

\begin{tabular}{|l|r|r|r|r|r|r|}
\hline $\begin{array}{l}\text { Description of } \\
\text { Three-Digit NAICS }\end{array}$ & $\begin{array}{l}\text { NAICS } \\
\text { Code }\end{array}$ & SOA_opp & R\&D_opp & PM_opp & PM_low & PM_high \\
\hline $\begin{array}{l}\text { Beverage and } \\
\text { Tobacco }\end{array}$ & 31212 & 0.179 & 0.051 & 0.231 & nd & nd \\
\hline $\begin{array}{l}\text { Beverage and } \\
\text { Tobacco }\end{array}$ & 31213 & 0.100 & 0.100 & 0.200 & nd & nd \\
\hline Chemical & 325110 & 0.208 & nd & nd & 0.210 & 0.430 \\
\hline Chemical & 325120 & 0.061 & nd & nd & 0.060 & 0.370 \\
\hline Chemical & 325180 & 0.300 & nd & nd & 0.310 & 0.450 \\
\hline Chemical & 325192 & 0.063 & nd & nd & 0.060 & 0.530 \\
\hline Chemical & 325193 & 0.087 & nd & nd & 0.090 & 0.640 \\
\hline Chemical & 325199 & 0.282 & nd & nd & 0.250 & 0.530 \\
\hline Chemical & 325211 & 0.178 & nd & nd & 0.180 & 0.470 \\
\hline Chemical & 325311 & 0.399 & nd & nd & 0.400 & 0.590 \\
\hline Chemical & 325312 & 0.086 & nd & nd & 0.070 & 0.460 \\
\hline Chemical & 325998 & 0.062 & nd & nd & 0.062 & 0.467 \\
\hline Food & 3112 & 0.349 & 0.000 & 0.349 & nd & nd \\
\hline Food & 311221 & 0.088 & 0.176 & 0.265 & nd & nd \\
\hline Food & 31131 & 0.450 & 0.281 & 0.732 & nd & nd \\
\hline Food & 3114 & 0.283 & 0.055 & 0.338 & nd & nd \\
\hline
\end{tabular}




\begin{tabular}{|c|c|c|c|c|c|c|}
\hline $\begin{array}{l}\text { Description of } \\
\text { Three-Digit NAICS }\end{array}$ & $\begin{array}{l}\text { NAICS } \\
\text { Code }\end{array}$ & SOA_opp & R\&D_opp & PM_opp & PM_low & PM_high \\
\hline Food & 3115 & 0.355 & 0.125 & 0.480 & nd & nd \\
\hline Food & 3116 & 0.289 & 0.096 & 0.386 & nd & nd \\
\hline Food & 3121 & 0.178 & 0.053 & 0.230 & nd & nd \\
\hline Food & 311 & 0.271 & 0.111 & 0.382 & nd & nd \\
\hline Food & 311224 & 0.349 & 0.000 & 0.349 & nd & nd \\
\hline Food & 311314 & 0.642 & 0.107 & 0.749 & nd & nd \\
\hline Food & 311313 & 0.347 & 0.376 & 0.723 & nd & nd \\
\hline Food & 311421 & 0.250 & 0.100 & 0.350 & nd & nd \\
\hline Food & 311411 & 0.302 & 0.029 & 0.331 & nd & nd \\
\hline Food & 311511 & 0.436 & 0.145 & 0.582 & nd & nd \\
\hline Food & 311512 & 0.600 & 0.200 & 0.800 & nd & nd \\
\hline Food & 311513 & 0.083 & 0.083 & 0.167 & nd & nd \\
\hline Food & 311514 & 0.400 & 0.000 & 0.400 & nd & nd \\
\hline Food & 31152 & 0.000 & 0.000 & 0.000 & nd & nd \\
\hline Food & 311612 & 0.281 & 0.063 & 0.344 & nd & nd \\
\hline Food & 311613 & 0.357 & 0.286 & 0.643 & nd & nd \\
\hline Food & 311615 & 0.200 & 0.000 & 0.200 & nd & nd \\
\hline $\begin{array}{l}\text { Mining (except Oil } \\
\text { and Gas) }\end{array}$ & 2121 & 0.204 & 0.371 & 0.575 & nd & nd \\
\hline $\begin{array}{l}\text { Mining (except Oil } \\
\text { and Gas) }\end{array}$ & 2122 & 0.244 & 0.458 & 0.702 & nd & nd \\
\hline $\begin{array}{l}\text { Mining (except Oil } \\
\text { and Gas) }\end{array}$ & 2123 & 0.339 & 0.211 & 0.550 & nd & nd \\
\hline Nonmetallic Mineral & 3272 & 0.325 & 0.086 & 0.410 & nd & nd \\
\hline Nonmetallic Mineral & 327211 & 0.218 & 0.105 & 0.323 & nd & nd \\
\hline Nonmetallic Mineral & 327212 & 0.289 & 0.099 & 0.388 & nd & nd \\
\hline Nonmetallic Mineral & 327213 & 0.489 & 0.042 & 0.531 & nd & nd \\
\hline Nonmetallic Mineral & 327993 & 0.180 & 0.139 & 0.319 & nd & nd \\
\hline Nonmetallic Mineral & 327310 & 0.338 & 0.036 & 0.373 & nd & nd \\
\hline Paper & 322110 & 0.465 & nd & nd & 0.470 & 0.742 \\
\hline Paper & 32212 & 0.445 & nd & nd & 0.445 & 0.608 \\
\hline $\begin{array}{l}\text { Petroleum and } \\
\text { Coal Products }\end{array}$ & 324110 & 0.132 & nd & nd & 0.140 & 0.400 \\
\hline Plastics and Rubber & 326140 & 0.200 & 0.051 & 0.251 & nd & nd \\
\hline Plastics and Rubber & 326211 & 0.149 & 0.136 & 0.285 & nd & nd \\
\hline
\end{tabular}




\begin{tabular}{|l|r|r|r|r|r|r|}
\hline $\begin{array}{l}\text { Description of } \\
\text { Three-Digit NAICS }\end{array}$ & $\begin{array}{l}\text { NAICS } \\
\text { Code }\end{array}$ & SOA_opp & R\&D_opp & PM_opp & PM_low & PM_high \\
\hline Plastics and Rubber & 3262 & 0.149 & 0.135 & 0.284 & nd & nd \\
\hline Plastics and Rubber & 326150 & 0.371 & 0.102 & 0.473 & nd & nd \\
\hline Plastics and Rubber & 326220 & 0.145 & 0.136 & 0.282 & nd & nd \\
\hline Plastics and Rubber & 326291 & 0.145 & 0.136 & 0.282 & nd & nd \\
\hline Plastics and Rubber & 326299 & 0.145 & 0.136 & 0.282 & nd & nd \\
\hline Plastics and Rubber & 326 & 0.315 & 0.083 & 0.398 & nd & nd \\
\hline Primary Metal & 331410 & 0.028 & 0.221 & 0.249 & nd & nd \\
\hline Primary Metal & 331110 & 0.388 & nd & nd & 0.390 & 0.630 \\
\hline Primary Metal & 331313 & 0.383 & 0.403 & 0.786 & nd & nd \\
\hline Primary Metal & 331314 & 0.667 & 0.037 & 0.704 & nd & nd \\
\hline Primary Metal & 331315 & 0.143 & 0.123 & 0.266 & nd & nd \\
\hline Primary Metal & 331318 & 0.143 & 0.123 & 0.266 & nd & nd \\
\hline
\end{tabular}

nd: Data not defined by bandwidth analysis. 